\title{
An Overview of Astrocyte Responses in Genetically Induced Alzheimer's Disease Mouse Models
}

\author{
Fokion Spanos ${ }^{1}$ (D) and Shane A. Liddelow $1,2,3, *$ D \\ 1 Neuroscience Institute, NYU Grossman School of Medicine, New York, NY 10016, USA; \\ fokion.spanos@student.uva.nl \\ 2 Department of Neuroscience and Physiology, NYU Grossman School of Medicine, New York, NY 10016, USA \\ 3 Department of Ophthalmology, NYU Grossman School of Medicine, New York, NY 10016, USA \\ * Correspondence: shane.liddelow@nyulangone.org
}

Received: 26 August 2020; Accepted: 2 November 2020; Published: 4 November 2020

check for updates

\begin{abstract}
Alzheimer's disease (AD) is the most common form of dementia. Despite many years of intense research, there is currently still no effective treatment. Multiple cell types contribute to disease pathogenesis, with an increasing body of data pointing to the active participation of astrocytes. Astrocytes play a pivotal role in the physiology and metabolic functions of neurons and other cells in the central nervous system. Because of their interactions with other cell types, astrocyte functions must be understood in their biologic context, thus many studies have used mouse models, of which there are over 190 available for $\mathrm{AD}$ research. However, none appear able to fully recapitulate the many functional changes in astrocytes reported in human AD brains. Our review summarizes the observations of astrocyte biology noted in mouse models of familial and sporadic AD. The limitations of AD mouse models will be discussed and current attempts to overcome these disadvantages will be described. With increasing understanding of the non-neuronal contributions to disease, the development of new methods and models will provide further insights and address important questions regarding the roles of astrocytes and other non-neuronal cells in AD pathophysiology. The next decade will prove to be full of exciting opportunities to address this devastating disease.
\end{abstract}

Keywords: Alzheimer's disease; astrocytes; reactive astrocyte; GFAP; mouse models; APP; Tau; ApoE; TREM2

\section{Introduction}

Alzheimer's disease (AD) is the most prevalent neurodegenerative disorder in adults, which manifests clinically through memory impairment and reduced cognition [1-3]. Even though it is a disease commonly associated with aging, the primary pathological features of disease, extracellular amyloid beta $(\mathrm{A} \beta$ ) plaques, and intracellular neurofibrillary tangles (NFTs) of Tau may be present twenty to thirty years prior to clinical symptoms of the disease being noticed [4]. More than ninety percent of AD cases are sporadic, of late onset (late-onset Alzheimer's disease-LOAD), and of unknown etiology. A minority are of autosomal dominant inheritance carrying mutations in genes that encode disease-associated proteins, such as the amyloid precursor protein (APP) and the presenilins (PSENs) 1 and 2, which cleave APP to produce A $\beta$ [5]. Analyses of families carrying these genes have allowed the formation of the major hypothesis that has driven AD research for the last twenty-five years. There is no evidence supporting a role for APP or PSEN genes in LOAD, but genome-wide association studies (GWAS) have identified almost 30 genes that make a statistically significant contribution to the genetic risk for the disease, with the APOE locus having the greatest impact.

Despite the high number of studies in human AD patients and animal models supporting a major role for $A \beta$ in disease development, there are no agents currently approved by the FDA for use in 
humans that are designed to inhibit $\mathrm{A} \beta$ production, its aggregation, or to enhance its clearance from the brain, and which effectively treat $\mathrm{AD}[6,7]$. This is most likely due to the high complexity of the disease, since several factors involving multiple genetic loci, cellular pathways, and environmental factors contribute to AD development [8]. Experimentally addressing each component individually followed by integrating the spatial, temporal, and kinetic interaction(s) among the different factors is a Herculean task. Since synaptic loss is a major feature of AD, the bulk of cellular studies have focused on primary events in AD neurons either in vivo or in cell culture after exposure to $A \beta$ or Tau aggregates. It has been recently appreciated that the other brain cell types-namely astrocytes, microglia, vascular endothelial cells, and pericytes-play a significant role throughout AD pathogenesis [9-12].

Astrocytes are at least as numerous as neurons in the human brain [13], although their numbers are reported to account for between 20 and $60 \%$ of brain cells, depending on the species and brain region [14-16]. Their physiological functions include metabolic support of neurons; maintenance of the integrity of the blood-brain barrier (BBB); and regulation of blood flow, synapse formation, and synaptic transmission (Figure 1) [17-21]. Changes in these important astrocyte functions occur in response to injury, infection, and chronic neurodegenerative disorders [22]. The astrocytic response during central nervous system (CNS) damage or disease, termed "astrogliosis" or astrocyte "reactivity", was first visualized using acidic dyes, and once antibodies had been produced by staining for glial fibrillary acidic protein (GFAP), an intermediate filament marker in astrocytes [23,24]. In humans, astrocyte reactivity is characterized by morphological changes (hypertrophy) and upregulation of GFAP, as evidenced by the increased GFAP-stained volume and branching per astrocyte. Similar changes in GFAP levels occur in mouse models of neurodegenerative diseases [25-28]. As molecular, biological, and transcriptomic analysis tools became more readily available, gene expression profiles have been used to characterize the astrocytic response. Early studies suggested that astrocyte reactivity was limited to a small number of distinct states dependent on the mode of the initiating injury $[29,30]$. However, this binary segregation of astrocyte function is controversial and astrocytes in different $\mathrm{AD}$ mouse models only partially resemble the complex heterogeneous reactive "sub-states" now reported in complex diseases such as $\mathrm{AD}$ [31-33]. In any case, various reactive astrocyte sub-states have been described surrounding amyloid plaques in mouse models of AD [34], and more recently in a number of single-cell or nuclei experiments in humans and mice [35-37]. These single-cell studies highlight the high degree of transcriptional heterogeneity, but due to a lack of in vitro models for individual reactive astrocyte sub-states, these transcriptomic discoveries have not yet been correlated with potential functional heterogeneity $[23,38]$.

To gain a better understanding of the cellular behavior and molecular response that occur during $\mathrm{AD}$, a large variety of mouse models have been generated (https://www.alzforum.org/research-models/ alzheimers-disease). These models shed light on astrocyte contributions to AD pathogenesis and pathology. Neurotoxicity, disrupted aquaporin 4 (AQP4) polarization, and altered $\mathrm{Ca}^{2+}$ signaling are some of the ways AD-associated gene mutations impede normal astrocyte function, which in turn are proposed to negatively impact neuronal health and function $[30,39,40]$. However, rodents do not naturally develop $\mathrm{AD}$, and insertion of several mutations of human genes into mice are required to recapitulate some of the pathological hallmarks present in human patients (i.e., $\mathrm{A} \beta$ plaques, neurofibrillary tangles, broadly defined "gliosis", neuronal death, synapse loss, electrophysiological changes, and cognitive impairment). This has been the subject of many reviews that have concluded that mice fail to recapitulate many aspects of human disease, highlighting a lack of model validity as the main cause of the lack of translatability of new model-based treatments to human patients [41-43]. 


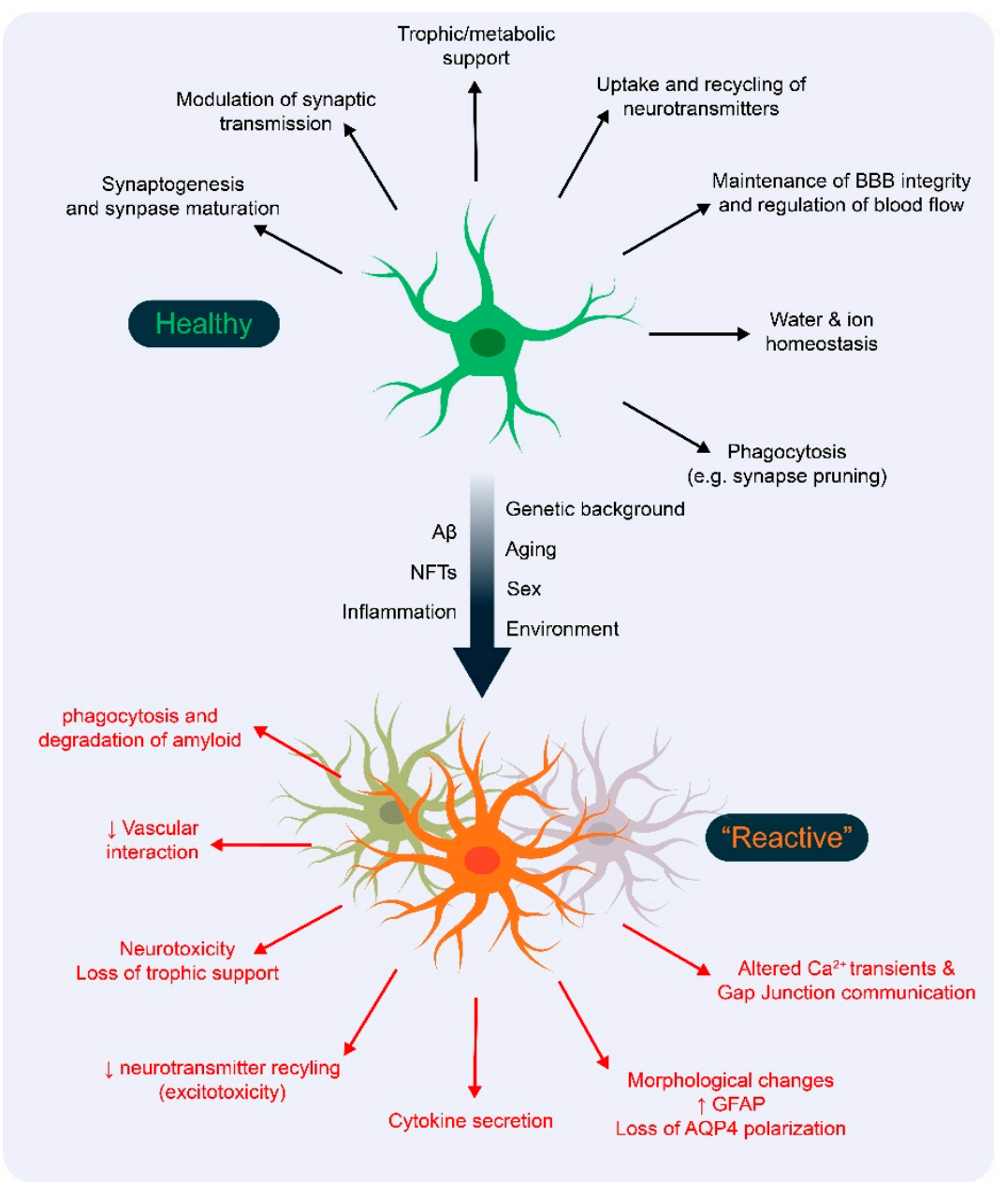

Figure 1. Summary of some main physiological functions of healthy astrocytes (top) and AD-induced changes in reactive astrocytes (bottom, multiple heterogeneous sub-states). Multiple AD-implicated risk factors (indicated next to the black arrow) contribute to changes in astrocyte function. The term "reactive" is representative of multiple reactive astrocyte sub-states that exist, each with differential functions, which are either beneficial or detrimental during AD pathogenesis. These sub-states may change according to disease progression, sex, aging, and underlying mutations or secondary pathology (e.g., inflammation). Abbreviations: $\mathrm{A} \beta=$ amyloid beta; $\mathrm{AD}=$ Alzheimer's disease; $\mathrm{AQP} 4=$ aquaporin 4 water channel; $\mathrm{BBB}=$ Blood-brain barrier, GFAP = glial fibrillary acidic protein; NFT = neurofibrillary tangles (of Tau).

One possible reason for limited mouse-to-human translatability is that the models, while modeling neuron pathology, do not fully recapitulate the glial and immune components of the human disease-likely due to a lack of markers and tools that can be used to understand how these cells change in humans. While non-neuronal cells have received some focus historically, the advent of new markers, specific genetic tools, and use of high-throughput transcriptomics has seen them gain more attention as possible active contributors to neurodegenerative disease. For instance, the involvement of neuroinflammation and vascular dysfunction as significant contributors to the development of $\mathrm{AD}$ is now widely accepted [44,45]. However, even when different aspects of AD involving multiple cell types are integrated and studied in mouse models, other factors can also affect disease progression. The genetic predisposition (in humans) or background (in mice) greatly influences AD pathogenesis [46,47]. For that reason, recent outbred and wild-derived AD mouse models have been created, which capture the human AD phenotypic heterogeneity and are believed to improve translatability and allow for personalized medicine. Additionally, cohort studies in mice where the 
influence of different genetic backgrounds and environmental factors (i.e., diet) are measured are helping to better understand how AD manifests, progresses, and can be treated [48]. The advent and wide availability of new methods and technologies has also contributed to our understanding of AD. Specifically, transcriptomics has allowed for high-throughput genetic sequencing at the cellular level, allowing development of various tools that can be used to better analyze the generated data and compare them across species [49-51]. One example includes generating a human co-expression network from AD and non-demented individuals. Then, the RNA sequencing data from one or multiple mouse models can be used to identify differentially expressed genes between transgenic and wild-type mice $[49,51]$. These genes can be overlapped with human genes in the co-expression network to identify which aspects of AD pathology a specific model recapitulates (i.e., cellular mechanisms, cell types involved). With over 190 genetically induced AD mouse models available, it is becoming difficult to keep track of what is already known about astrocytes in $\mathrm{AD}$, whether the findings are comparable between studies, and what should be addressed next. It is also critical to consider the differences between mouse and human biology and between transgenic models and human AD brains. Do astrocytes respond and behave similarly in humans with AD and in mouse models of $\mathrm{AD}$ ? Does the endogenous astrocyte population differ between age-comparable naïve humans and mice? Does aging, the highest risk factor for developing $\mathrm{AD}$, differentially contribute to disease progression similarly in humans and mice? What are the advantages and limitations of current AD mouse models? Can these models be improved to increase their translatability? Our review will address these questions in the context of summarizing the main in vivo findings on astrocytes across AD mouse models (see supplementary information regarding literature search) and comparing them with what is known from studies in human AD brains.

\section{Astrocyte Responses in Genetically Induced AD Mouse Models}

The first attempts to model AD pathology in mice took advantage of overexpression of mutated human genes involved in familial AD (FAD). Most of these transgenic (Tg) lines recapitulate some, but not all, aspects of AD pathology. For instance, models with mutations in the APP and PSEN genes tend to develop extracellular $A \beta$ plaques but in multiple models there is no neuronal loss (e.g., APPswe/PSEN1dE9, APPNL-G-F) [52,53]. While Tau may be phosphorylated in some of these models (e.g., APP23 [54]), as a rule there is no evident formation of Tau tangles, even though a number of Tau AD models, but not all, display substantial neuronal loss (e.g., rTg4510, PS19) [52,53]. Human Tau and its mutant forms have also been overexpressed in mice. Again, while these mice may develop tangles, they do not show other features of $\mathrm{AD}$ pathology such as $\mathrm{A} \beta$ plaques, but several do develop neuronal loss [55]. As a response to this apparent experimental fragmentation, APP, PSEN, and Tau transgenes have been combined to form unique experimental strains [56,57]. Using different cell-type-specific promoters, the transgenes can be expressed in different cells (e.g., Thy1 promoters for neurons, Gfap for astrocytes [58]), allowing for a better mechanistic approach to the understanding of how expression of AD-associated genes affects each cell type, and as a result determination of their contribution to AD pathogenesis. To overcome any issues caused by transgene overexpression, which were common in the early AD models, various knock-in (KI) models, such as APPNL-F (knock-in of humanized APP sequence introns 15-17 containing the Swedish and Beyreuther or Iberian mutations [59]), have also been generated. Another major concern involves the type of AD being modeled (familial or sporadic). Most mouse models mimic features of FAD cases, which constitute a relatively small portion of the total number of patients, under the assumption that all or some elements of pathogenesis would be shared with the more common sporadic or LOAD, since the major pathologic features of both are the $A \beta$ plaque and neurofibrillary tangles.

Genetic studies in LOAD patients showed that apolipoprotein-E (APOE) is a major genetic risk factor for developing LOAD and individuals carrying the $\varepsilon 4$ allele (APOE4) are more likely to develop the disease and at an earlier age [60]. The observation made with a traditional genetic approach has been reproduced many times in multiple GWAS, which have also identified almost 
thirty additional independent loci that are associated with susceptibility to LOAD across different human populations [61-63]. The relevance of studying astrocytes in the context of transgenic models of human AD is apparent in the context of the GWAS analyses, which have defined several AD-risk genes, the expression of which are enriched in astrocytes in the CNS (e.g., APOE, CLU, SERPINA1, CXCL16) $[64,65]$.

\subsection{Familial Alzheimer's Disease Mouse Models}

\subsubsection{Models Involving the APP Pathway}

APP is naturally cleaved into A $\beta$ peptides by the sequential activities of the $\beta$ - and $\gamma$-secretases [5]. PSEN1 and PSEN2 are subunits of $\gamma$-secretase, which participate in APP cleavage [66,67]. The classical $\mathrm{AD}$ amyloid hypothesis (with its periodic updates) proposes that there is an increase in $\mathrm{A} \beta$ production (particularly the longer forms of the peptide) or decrease of its clearance, with the increased concentration promoting $A \beta$ aggregation [68]. The aggregates are found both intra- and extra-cellularly, and when outside the cell form $\mathrm{A} \beta$ plaques. Initial observations in $\mathrm{AD}$ patients and later in mouse models indicated the presence of "reactive" astrocytes stained with GFAP around A $\beta$ plaques $[28,69]$. These early studies reported that most mouse models displayed some form of astrogliosis [69,70]—namely increased GFAP protein or Gfap gene levels in the cortex and hippocampus [26,71-78]. However, later studies showed that this finding varied in the context of the age, brain region, sex, and methods used to quantify GFAP or Gfap levels (e.g., Western blot or quantitative polymerase chain reaction, GFAP signal intensity of number of GFAP+ cells) in each model (Table 1 and Supplementary Table S1) [79-81].

The most studied AD mouse model, APPswe/PSEN1dE9, carries two transgenes, human APP with the Swedish mutation and human PSEN1 lacking exon 9, both under the control of the mouse prion promoter (see Table 2). These mice develop plaque pathology and synaptic loss around 4 months of age [82-84], with cognitive impairment appearing by 6 months [82]. Astrogliosis is seen at 6 months, as assessed by increases in GFAP protein levels and in the GFAP+ cell number in the cortex of Tg compared to wild-type (WT) or younger mice [26,72-79,85]. Hippocampal samples of mice at the same age also showed elevated GFAP protein levels, a finding not noted in all studies [79]. These differences could be methodologic (e.g., measurements of GFAP) or biologic (e.g., sex related). In humans, females are more prone to developing AD [86]. In Tg2576 and 3xTg mouse models, males tend to develop plaque pathology later than female mice, while female $3 \times \mathrm{Tg}$ have more NFT pathology compared to males [87-89]. In APPswe/PS1dE9 mice, females have increased GFAP levels, reduced adult-born neuronal spines, and impaired spatial memory compared to males at 7-9 months of age [71]. Furthermore, GFAP+ astrocytes have increase branch length and number of branches in female APPswe/PS1dE9 mice versus WT, while such morphological changes are not observed in male transgenic mice at 7-9 months of age. Another example includes increased astrocytic gamma-aminobutyric acid (GABA) release by reactive astrocytes in the hippocampus and monoamine oxidase $\mathrm{B}(\mathrm{MAOB})$ activity, an enzyme which participates in GABA production, in 18-month-old female 5xFAD mice [90]. However, it should be noted that the above data (A $\beta$ and NFT pathology, the astrocytic morphology and GFAP levels, and GABA levels) have not been validated in female versus male $A D$ patients. Thus, while studies in mouse models suggest some potential explanations for the sex differences accounting for human AD prevalence, further investigation in human samples is necessary in order to validate the data. Additional complexity may also come from changes induced by housing conditions-as shown recently in amyloid mouse, rat, and D. melanogaster models of AD where microbiome changes caused different pathological and behavioral readouts (see [91] for review). 
Table 1. Reported changes in the GFAP, AQP4, complement pathway, and cytokines in astrocytes from APP or PSEN mouse models. All comparisons are versus age-matched, wild-type mice, unless otherwise mentioned. For more information on the genetic background models see Table 2 . For a full overview in APP and/or PSEN mouse models see Supplementary Table S1. For an overview of astrocyte responses in Tau mouse models see Supplementary Table S2.

\begin{tabular}{|c|c|c|c|c|}
\hline Finding & Method & Age & Brain Area & References \\
\hline \multicolumn{5}{|c|}{ Tg(APPswe/PSEN1dE9) (also known as 2xTg, 2xTg-AD, APP/PS1) } \\
\hline $\begin{array}{l}\uparrow \text { GFAP protein (including staining intensity) } \\
\text { (for male vs. female see [71,92]) }\end{array}$ & WB, IHC & $\begin{array}{c}6-19 \mathrm{mo} \\
3 \mathrm{mo}(\mathrm{HPC})\end{array}$ & $\begin{array}{c}\text { CTX, HPC } \\
\text { STR, CB (19 mo })\end{array}$ & {$[26,72-76,93]$} \\
\hline$\uparrow$ GFAP+ cell density & IHC & $\begin{array}{c}6,12-14,23-28 \mathrm{mo} \\
? 6,12-14 \mathrm{mo} \\
3 \mathrm{mo} \\
16 \mathrm{mo} \\
\end{array}$ & $\begin{array}{c}\text { CTX } \\
\text { HPC } \\
\text { DG } \\
\text { CA3 }\end{array}$ & {$[26,73,79,85]$} \\
\hline$\downarrow$ GFAP+ cell density & IHC & $24 \mathrm{mo}$ & HPC & [80] \\
\hline NC GFAP+ cell density & IHC & $5-9 \mathrm{mo}$ & CTX layers II/III & [81] \\
\hline$\uparrow \mathrm{GFAP}+$ area in $8-12 \mathrm{mo}$ & IHC & $2-6,8-12 \mathrm{mo}$ & FtC, HPC & [77] \\
\hline$\downarrow$ GFAP+ area & IHC & $24 \mathrm{mo}$ & HPC & [80] \\
\hline NC GFAP+ cells/blood vessel & IHC & $6,12-14,23-28 \mathrm{mo}$ & HPC & [79] \\
\hline $\begin{array}{l}\text { NC A1, A2, pan-reactive genes } \\
235 \text { genes differentially expressed [ } \uparrow \text { Cytokines/Chemokines (Il1 } \beta, C c l 2, C c l 4, C c l 6) \text {, } \\
\text { Complement }(C 1 q a, C 1 q b, C 1 q c, C 4 b)]\end{array}$ & $\begin{array}{l}\text { RNA-seq of FACS-isolated } \\
\text { astrocytes }\end{array}$ & $9 \mathrm{mo}$ & HPC & [94] \\
\hline No uptake of Methoxy-X04+ amyloid fibrils by astrocytes & FACS & $9 \mathrm{mo}$ & HPC & [94] \\
\hline Fibrillar A $\beta$ not engulfed by GFAP+ cells & IHC & $3,6,9,12 \mathrm{mo}$ & CTX, HPC & [73] \\
\hline \multicolumn{5}{|c|}{$\operatorname{Tg}($ APPSwLon/PSEN1*M146L) } \\
\hline GFAP+ cells engulf APP+ dystrophic neurites & IHC, EM & $4,6,12 \mathrm{mo}$ & HPC & [95] \\
\hline \multicolumn{5}{|c|}{ Tg(PDGFB-APPSwInd) (also known as hAPP-J20, APP/J20, J20) } \\
\hline$\uparrow$ GFAP+ area from $12-29 \mathrm{mo}$ & $\mathrm{IHC}$ & $3,9,12-16,29 \mathrm{mo}$ & CTX & [96] \\
\hline$\downarrow$ GFAP+ surface/volume per cell & IHC & $5 \mathrm{mo}$ & HPC & [97] \\
\hline NC GFAP+ cell surface and volume & IHC & $5 \mathrm{mo}$ & HPC & [97] \\
\hline $\begin{array}{l}\text { Observations: Vascular amyloidosis can partially or fully displace astrocyte endfeet } \\
\text { from vessels }\end{array}$ & IHC, EM & $27 \mathrm{mo}$ & CTX & [96] \\
\hline \multicolumn{5}{|c|}{ Tg(Thy1-APPSw/Prnp-PSEN2*N141I) (also known as PS2APP) } \\
\hline$\uparrow$ GFAP+ area & IHC & $6 \mathrm{mo}$ & HPC & [33] \\
\hline $\begin{array}{c}\uparrow \text { classical components ( } \uparrow C 1 q \text { in RNA-seq, but not NC fluorescence intensity in IHC) } \\
\text { NC C3 expression } \\
\uparrow A 1 \text {-specific and pan-reactive genes }\end{array}$ & $\begin{array}{l}\text { RNA-seq of FACS-isolated } \\
\text { astrocytes (validated with IHC) }\end{array}$ & $7,11.5,13 \mathrm{mo}$ & HPC & [33] \\
\hline
\end{tabular}


Table 1. Cont

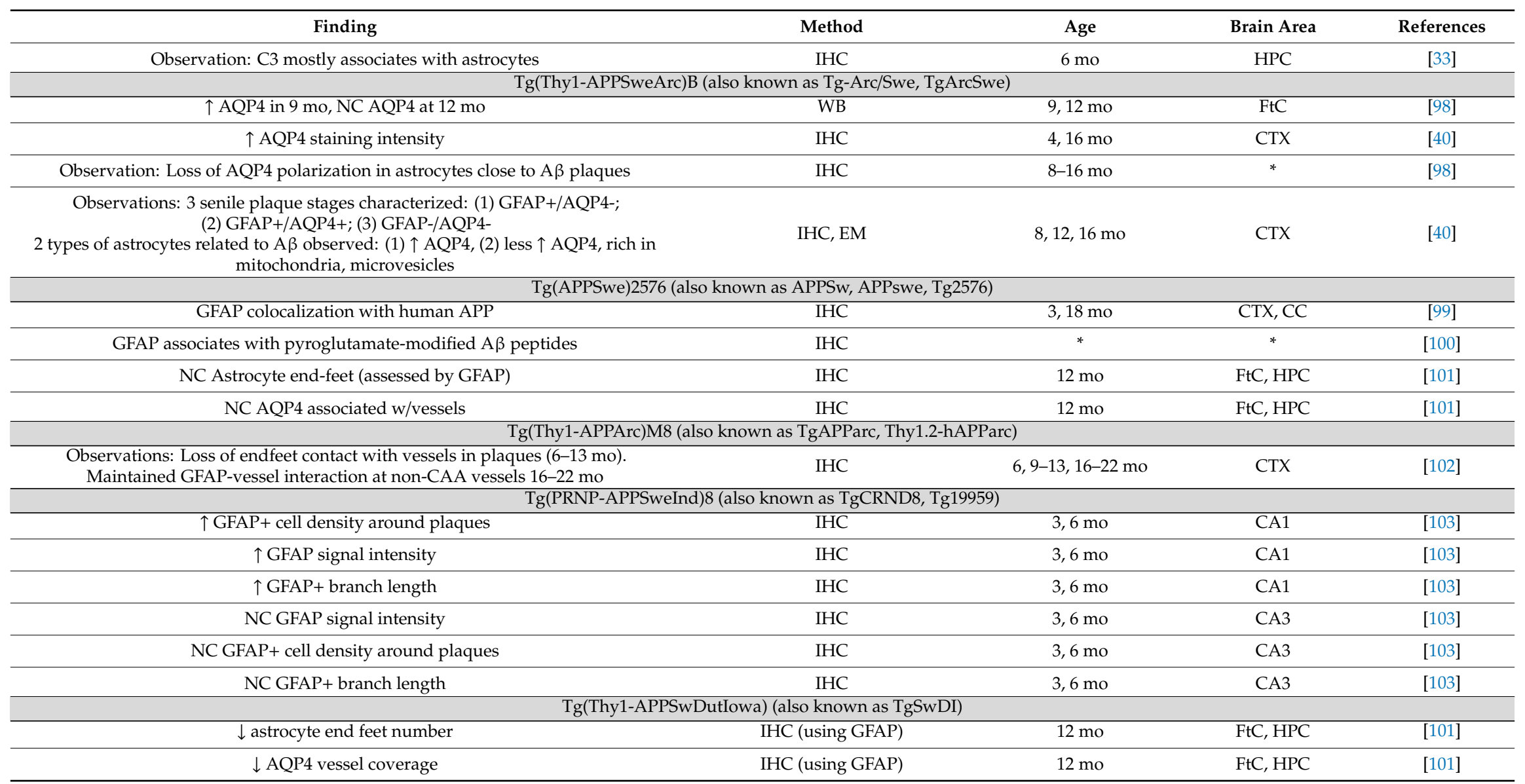

Abbreviations: $\uparrow=$ upregulation; $\downarrow=$ downregulation; NC $=$ no significant change; $?=$ contradicting data; ${ }^{*}=$ missing data; A $\beta=$ amyloid beta; APP $=$ amyloid precursor protein; $\mathrm{CB}=$ cerebellum; $\mathrm{CA}=$ Cornu Ammonis; $\mathrm{CTX}=$ cortex; $\mathrm{DG}=$ dentate gyrus; $\mathrm{EM}=$ electron microscopy; $\mathrm{EC}=$ entorhinal cortex; FACS = fluorescence-activated cell sorting; FtC = frontal cortex; HPC = hippocampus; IHC = immunohistochemistry; mo = months old; NC = no significant change; STR = striatum; WB = Western blot; WT = wild-type. For additional mouse genome synonyms we recommend referring to $w w w$.informatics.jax.org. 
Apart from being used as a general marker for astrogliosis (i.e., measuring the number of cells expressing GFAP or signal intensity within a cell), GFAP has also helped characterize astrocyte morphology in the context of AD. The GFAP+ cell surface and volume were not significantly altered in the hippocampus of 5-month-old hAPP-J20 mice [97], which express human APP with the Swedish and Indiana mutations under the control of the human platelet-derived growth factor- $\beta$ promoter. Nevertheless, the GFAP+ surface-to-volume ratio per cell was significantly reduced, indicating individual astrocyte GFAP morphology changes during progression in this model [97]. As GFAP can also stain astrocyte primary processes, the marker was used to measure the astrocyte branch length in the cornu ammonis 1 (CA1) and CA3 hippocampal areas of TgCRND8, which express human APP with the Swedish mutation and Indiana mutations, respectively, under the control of the hamster prion gene promoter. The GFAP+ branch length of the CA1 but not CA3 astrocytes at 3 - and 6-month-old TgCRND8 mice was increased [103]. This is possibly due to the induction of reactive astrogliosis in the CA1, as assessed by the elevated GFAP signal intensity and number of GFAP+ cells. As astrocytes have distinct territorial domains that do not overlap extensively with neighboring astrocytes [104], it would be interesting to address how these domains are altered during $\mathrm{AD}$ and determine the functional outcomes of such morphological changes. Additionally, findings regarding astrocyte morphology in AD mouse models restricted to GFAP measurements, which is an intermediate filament protein, do not mark all of the astrocyte branching terminal processes, nor do they explain how the astrocyte function is changed. Therefore, GFP reporters or synaptic markers can be employed to analyze astrocyte morphology and complexity (i.e., Sholl analysis, coverage of synapses) [105]. Knowing that astrocytes undergo distinct morphological changes in disease contexts, detailed microscopy analysis could be pivotal in determining these alterations and how they are related to their altered function. 
Table 2. Genetic background of FAD mouse models discussed in the review. Late-onset Alzheimer's disease models are not included here, as the genetic manipulation is indicated in the model's name (e.g., human GFAP-APO 4 = APO $\varepsilon$ allele 4 driven by the GFAP promoter). APP695, 751, and 770 refer to different APP isoforms generated by alternative splicing of exons 7 and $8 .{ }^{*}$ All mice are transgenic, except for 3xTg, where PSEN1 was knocked-in. For additional information on these models and the models in Supplementary Tables S1-S3, please visit (https://www.alzforum.org/research-models/alzheimers-disease). For ease of reading, we will refer to the shortened model name (left hand column) throughout the review. Addition synonyms can be found at www.informatics.jax.org.

\begin{tabular}{|c|c|c|c|c|}
\hline Model & Gene(s) & Mutation(s) & Promoter & References \\
\hline mThy1-hAPP751 & $A P P$ & APP751; Swedish (K670N/M671L) and London (V717I) & mThy1 & [106] \\
\hline $\operatorname{Tg} 2576$ & $A P P$ & APP695; Swedish (K670N/M671L) & Hamster Prnp & [107] \\
\hline TgAPParc & $A P P$ & APP695; Arctic (E693G) & mThy1.2 & [108] \\
\hline TgArcSwe & $A P P$ & APP695; Arctic (E693G) and Swedish (KM670/671NL) & mThy1 & [109] \\
\hline TgSwDI & $A P P$ & APP770; Swedish (K670N/M671L), Dutch (E693Q) and Iowa (D694N) & mThy1 & [110] \\
\hline $5 x F A D$ & APP, PSEN1 & $\begin{array}{l}\text { APP695: Swedish (K670N/M671L), Florida (I716V), London (V717I) } \\
\text { PSEN1: M146L and L286V }\end{array}$ & mThy1 & [111] \\
\hline APPPS1 & APP, PSEN1 & $\begin{array}{l}\text { APP751: Swedish (K670N/M671L) } \\
\text { PSEN1: L166P }\end{array}$ & mThy1.2 & [112] \\
\hline APPswe/PSEN1dE9 & APP, PSEN1 & $\begin{array}{l}\text { APP695: Swedish (K670N/M671L) } \\
\text { PSEN1: exon } 9 \text { removed }\end{array}$ & $\mathrm{m}$ Prnp & {$[113,114]$} \\
\hline 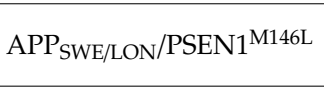 & APP, PSEN1 & $\begin{array}{l}\text { APP751: Swedish (K670N/M671L) and London (V717I) } \\
\text { PSEN1: M146L }\end{array}$ & $\begin{array}{l}\text { mThy1 (APP) } \\
\text { HMG (PSEN1) }\end{array}$ & [115] \\
\hline PSEN2APP & APP, PSEN2 & $\begin{array}{l}\text { APP751: Swedish (K670N/M671L) } \\
\text { PSEN2: N141I }\end{array}$ & $\begin{array}{l}\text { mThy1.2 } \\
\text { mPrnp }\end{array}$ & [116] \\
\hline PS19 & MAPT & MAPT (1N4R): P301S & mPrnp & [117] \\
\hline $\mathrm{Tau}^{\mathrm{R} 406 \mathrm{~W}}$ & $M A P T$ & $\begin{array}{l}\text { MAPT (2N4R): R406W, contains myc and FLAG tags at N-and C-terminal } \\
\text { ends, respectively }\end{array}$ & CamkII & [118] \\
\hline $\mathrm{Tau}^{\mathrm{P} 301 \mathrm{~L}}$ & MAPT & MAPT (2N4R): Tau-4R/2N isoform; P301L & mThy1 & [118] \\
\hline $\operatorname{rTg} 4510$ & $M A P T$ & MAPT (0N4R): P301L & $\begin{array}{c}\text { tetO } \\
\text { CaMKII } \alpha \text {-tTA }\end{array}$ & {$[119,120]$} \\
\hline rTgTauEC & $M A P T$ & MAPT (0N4R): P301L & $\begin{array}{c}\text { tetO } \\
\text { Neuropsin-tTA }\end{array}$ & {$[121,122]$} \\
\hline $3 \times \mathrm{Tg}$ & APP, PSEN1, MAPT & $\begin{array}{c}\text { APP751: Swedish (K670N/M671L) } \\
\text { PSEN1: M146V } \\
\text { MAPT (0N4R): P301L }\end{array}$ & $m$ Thy $1 *$ & [57] \\
\hline
\end{tabular}


Thus, while we restrict the discussion largely to GFAP in this review, these data indicate that it is important to standardize experimental designs (e.g., age tested, environmental conditions) within a model in order to be able to make comparisons between studies.

Despite complications related to experimental standardization and GFAP, AD mouse models have been useful. The use of GFAP as an astrocyte marker extends to immunohistochemical colocalization with other markers to relate astrocytes with potentially AD-altered cellular functions. For instance, immunostaining of GFAP and Ki67 or BrdU, which are used to measure proliferation, did not cause colocalization in human $\mathrm{AD}$ or $\mathrm{A} \beta$ mouse models [78,123-125], suggesting significant proliferation of astrocytes does not occur in this context. Thus, it could be argued that the reported increased numbers of GFAP+ astrocytes in AD model mice and humans are most likely due to the induction of Gfap expression in GFAP- astrocytes. While GFAP, which is used as a broad marker of reactivity, has helped correlate changes in astrocytes with $\mathrm{AD}$ pathology in vivo (e.g., $\mathrm{A} \beta$ plaques), a disadvantage of using GFAP alone remains, namely that astrocytes maintain heterogeneous levels of GFAP across brain regions, development, and in multiple reactive sub-states [22,126,127]. What would be more useful for understanding astrocyte responses to $\mathrm{AD}$ pathologies would be unbiased transcriptomic or proteomic analysis of heterogeneous states and functional characterization of these subtypes where possible.

To gain better insight into the functional effects of $A \beta$ and its aggregates on astrocytes in vivo, studies have addressed astrocyte functionality by measuring the electrophysiology, calcium transient parameters, gap junctional communication, glutamate uptake, expression and release of cytokines and growth factors, AQP4 localization, and A $\beta$ uptake and clearance (Supplementary Table S1). Interestingly, there are conflicting results regarding $A \beta$ uptake in vivo, despite the fact that studies have indicated that astrocytes can phagocytose $A \beta$ in vitro and in situ and have identified mechanisms of action [128-130]. Additionally, Xiao et al. (2014) [128] drove exogenous expression of the transcription factor EB ( Tfeb) in astrocytes (using the Gfap promoter) of 2-month-old APPswe/PSEN1dE9 mice. While TFEB induced lysosome biogenesis and enhanced uptake of $A \beta 42$ by astrocytes in vitro, in vivo expression led to a decrease of PBS-soluble and -insoluble $A \beta 40$ and $A \beta 42$ fractions, probably via the same pathway. Further, immunohistochemical colocalization of GFAP and A $\beta$ plaques and electron microscopy indicated engulfment of APP dystrophic neurites $[95,99,100]$. However, fluorescence-activated cell sorting (FACS) of MX04 (Methoxy-X04)-labelled plaques and tangles revealed $\mathrm{A} \beta$ within $\mathrm{CD} 11 \mathrm{~B}+/ \mathrm{CD} 45+$ microglia and not $g f a A B C 1 D$-driven (a Gfap-derived synthetic promoter [131]) GFP+ hippocampal astrocytes at 9 months of age in APPswe/PSEN1dE9 mice [94]. Whether the difference is due to the methodology (MX04 stains A $\beta$ plaques) or is a function of the studied model is not clear. Additional studies directly testing whether astrocytes phagocytose amyloid in vivo are necessary, and it should also be determined whether the mechanisms identified in vitro are also involved in $A \beta$ uptake in vivo.

$A \beta$ clearance across the BBB is well documented (for a review on $A \beta$ clearance mechanisms see [124]), and astrocytes are implicated through their AQP4 water channels [132]. However, it has been shown that $A \beta$ impairs AQP4 channel function, meaning that increased exposure to $A \beta$ could feed back to impair its proper clearance in later stages of the disease [133]. In Tg-Arc/Swe transgenic mice (expressing human APP containing both the Arctic and Swedish mutation), an overall increase was shown in AQP4 protein levels in the cortex of 9-month-old mice compared to WT age-matched control animals $[40,98]$. The increase was preserved in older mice (up to 16 months old), as measured by AQP4 immunofluorescence intensity, although Western blotting showed no differences between the frontal cortex of 16-month-old Tg-Arc/Swe and WT mice [98]. The increase was accompanied by loss of AQP4 polarization within astrocytes close to $\mathrm{A} \beta$ plaques. Using electron microscopy, Yang et al. (2011) [40] characterized three stages of astrocytes surrounding A $\beta$ plaques. GFAP+/AQP4- astrocytes were present at early plaque stages, followed by GFAP+/AQP4+, and lastly GFAP-/AQP4- astrocytes, which became more prominent in older mice. The functional relevance of these different populations was not addressed, but it seems that GFAP increases before AQP4. Future studies addressing whether the three astrocytic populations correlate with the stage of each plaque's appearance could help in 
understanding how $A \beta$ impacts astrocyte function. Perhaps the first two populations are different states of reactive astrocytes, while GFAP-/AQP4- astrocytes are atrophic. Studies in other models have measured AQP4 levels, the area covered, and AQP4's association with vessels in order to gain further insight into A $\beta$ 's effect on AQP4, but the results vary across models. The 12-month-old Tg2576 (transgenic expression of human APP containing the Swedish mutation) mice had identical numbers of AQP4+ astrocytic endfeet (stained with GFAP) in the frontal cortex and hippocampus compared to WT mice [101]. The same study found a significant reduction in both parameters in Tg-SwDI mice of the same age. The reduced association of astrocytes with vessels could be both indirect and direct. For instance, vascular amyloidosis can directly displace astrocyte endfeet from vessels [96]. Furthermore, the GFAP-vessel interaction is maintained in vessels without cerebrovascular amyloid angiopathy (CAA) in 16-22-month-old TgAPParc (human APP with the Arctic mutation) mice [102]. Since Aqp $4^{--}$APP/PSEN1dE9 mice have increased A $\beta$ accumulation [134], it is most likely that this accumulation impairs normal AQP4 levels and function, leading to enhanced $\mathrm{A} \beta$ pathology. It is not known if the findings in the different models also reflect possible differences among AD patients carrying distinct FAD mutations. Future studies are necessary to determine this and should determine the effects that different mutations have on specific astrocyte functions.

A substantial amount of progress has been made in examining the effect of $A \beta$ on astrocyte function in vivo. However, there are still key knowledge gaps. For instance, we still do not know if the discrepancies regarding AQP4 findings between models reflect variability within the human population or if they are simply an artifact of our current rodent models. Most of these models express the transgenes (APP, PSEN1, PSEN2) above physiological levels and recapitulate some of AD's pathological hallmarks, thus their translatability could be compromised. While some studies have attempted to validate results in both mice and humans-for example, GFAP/Ki67 colocalization analyses-others have not. Electrophysiological studies, for example, cannot be performed in post-mortem human brains, although it is possible to use human neuronal cultures, and in particular human iPSC-derived organoids [135-137]. Some of the recent methods and their discoveries regarding astrocyte function in $\mathrm{AD}$ will be briefly discussed later in Section 4. For an overview of astrocyte findings in APP and/or PSEN mouse models see Supplementary Table S1.

\subsubsection{Models Involving the MAPT Gene}

Tau (encoded by MAPT) is a microtubule-associated protein expressed mostly in neurons. The degree and sites of Tau phosphorylation determine its ability to bind to microtubules and regulate their polymerization [138]. In AD, phospho-Tau increases and forms NFTs [139], causing disruption of axonal transport and cell death [139]. Mouse models carrying human MAPT mutations have increased phosphorylated Tau levels, many of which display neurofibrillary tangles, in contrast to APP and PSEN1 transgenic and knock-in mouse models, which do not (for an overview of these models see https://www.alzforum.org/research-models/alzheimers-disease.

Similar to amyloid models (see above), Tau phosphorylation and oligomer formation induces astrocyte reactivity in mice [140-144]. The age of onset for reactive astrogliosis, as measured by the signal intensity, area covered by GFAP, or number of GFAP+ astrocytes, varies across the Tau models and brain regions studied. These differences may manifest due to models being based on mutations, overexpression, and the spatial distribution of the transgene being expressed. For example, PS19 mice (expressing human Tau ${ }^{\mathrm{P} 301 \mathrm{~S}}$ under the control of the mouse prion protein promoter) develop cortical astrogliosis as early as 3 months [140], while rTg4510 mice, which overexpress Tau ${ }^{\mathrm{P} 301 \mathrm{~L}}$ mainly in forebrain neurons and show prominent neuronal loss and formation of NFTs [119,120,144,145], develop astrogliosis from 2.5 months of age [144]. In rTgTauEC mice, which overexpress Tau ${ }^{\text {P301L }}$ only in a subset of entorhinal neurons, increased number of GFAP+ cells in the entorhinal cortex is seen at 14 months of age [142]. In PS19 mice, astrogliosis in the dentate gyrus and the CA1 and CA3 regions of the hippocampus appears at 9 months of age ( 6 months later than in the cortex), as measured by GFAP-stained area [141]. Overall, the distribution and density of NFTs 
correlate with those of GFAP, suggesting a relationship between aberrant Tau and astrogliosis [117]. Interestingly, hyperphosphorylated Tau is present in the caudal cortex, entorhinal cortex, and CA3 from 3 months of age in PS19 mice, even though astrogliosis in CA3 develops later [141]. This could be due to selective vulnerability of different brain regions to AD pathology, which is further evidenced in rTgTauEC mice, where Tau pathology is seen in brain areas with direct connection to the entorhinal cortex (the hippocampal and para-hippocampal areas, the amygdala, and the perirhinal cortex) in the absence of measurable astrogliosis (although it is present in the amygdala) [142]. Thus, it seems that the presence of aberrant Tau forms does not always cause immediate astrogliosis.

The presence of more well-defined astrogliosis in Tau models has been shown using unbiased RNA sequencing of hippocampal astrocytes [33]. Here, PS19 astrocytes upregulated genes associated with a pro-inflammatory A1-specific set of genes, as well as genes associated with several reactive states and genes involved in the classical complement pathway (C1q, C4b, C3, and Serping1), which could contribute to neurodegeneration. Silencing C3 (a complement component involved in inflammation and cell lysis [146]) using global knock-out $\left(\mathrm{C}^{-/-}\right)$prevented Tau-induced neuronal death in PS19 mice [33]. It was also reported that in $\mathrm{C}^{-/-} \times$PS2APP (human APP with the Swedish mutation and PSEN2 ${ }^{\mathrm{N} 141 \mathrm{I}}$ ) mice, neuronal synaptic loss in proximity to $A \beta$ plaques is reduced. Additionally, $\mathrm{C} 3$ receptor, C3aR, mRNA, and protein levels are increased in PS19 mice [147]. C3ar ${ }^{-1-}$ partly reduces the Tau pathology and GFAP+ area in 9-month-old PS19 mice, among others. Mechanistically, the C3 receptor, C3aR, induces STAT3 phosphorylation [147]. When the transcription factor STAT3 is phosphorylated, it translocates to the nucleus to induce transcriptional changes in some subsets of reactive astrocytes $[22,148]$. Nevertheless, the $\mathrm{C}^{-/-}$rescue in PS2APP and PS19 mice may not have been astrocyte-specific, since microglia, which are also implicated in neuroinflammation and neuronal death, can upregulate $C 3$. Microglia and astrocytes interact in the brain, and activation of microglia can induce astrocyte reactivity, which is predicted to drive neuron death $[30,149]$. Thus, the presence of $A \beta$ or Tau aggregates is likely to trigger both cell types to become reactive. The exact mechanisms of $A \beta$ - and Tau-induced astrocyte and microglia activation are not yet known, but these results further suggest that targeting the inflammatory cascade could be a valid strategy for drug development in AD.

Tau hyperphosphorylation is reported in brain regions directly connected with the entorhinal cortex in rTgTauEC mice [142]. This is because Tau aggregates, which are largely composed of the phosphorylated protein, can be transmitted from one neuron to another [150-152] through possible synaptic vesicle release across the synaptic cleft [153]. Astrocyte endfeet are in close association with these synaptic clefts (forming the "tripartite" synapses [17,154]), suggesting they may also play a role in Tau seeding. Tau uptake by astrocytes is evident in in vitro cultures [155], and in AD patients it appears that some astrocytes contain NFTs [156]. To test whether aberrant neuronal Tau can be transmitted to astrocytes, cortical and hippocampal brain sections from $\mathrm{Tau}^{\mathrm{R} 406 \mathrm{~W}}$ transgenic mice (which express human Tau in excitatory neurons under the control of the CamkII promoter) were used [157]. Using this mouse model, astrocytes did not stain with antibodies specific for human Tau. However, astrocytes did contain mouse Tau. Similarly in Tau ${ }^{\mathrm{P} 301 \mathrm{~L}}$ mice, expressing human Tau in neurons under the control of the Thy1 or mouse prion protein promoters, saw GFAP+ astrocytes contain or associate with oligomeric and filamentous human Tau [158,159], implying that some astrocytes indeed show Tau pathology. However, Tau aggregates from human AD patients do not display Tau inclusions in glial cells [158], thus additional experiments are necessary to identify the extent to which Tau uptake occurs in AD, which Tau forms are taken up by astrocytes, and by which mechanism. Do different MAPT mutations influence astrocyte uptake of Tau? What is the effect of aberrant Tau formation in astrocytes? Does astrocyte-expressed Tau, albeit at low levels, contribute to AD pathology? These are some of the questions that should be answered to gain a better understanding of Tau-induced astrocyte pathology.

Similar to models that only contain APP/PSEN1 mutations, mice bearing only a mutant MAPT gene may not fully recapitulate astrocyte functional deficits. Tau models provide a great tool to understand how abnormal Tau levels or forms impair normal astrocyte function, but caution should 
be taken when translating findings to human $\mathrm{AD}$, where there is extensive $\mathrm{A} \beta$ pathology and Tau phosphorylation appears to be a downstream event. To better model AD pathology, models with mutations in $A P P, P S E N$ s, and MAPT genes have been developed. One such model, the triple transgenic model (3xTg, knock-in of human PSEN1 ${ }^{\mathrm{M} 146 \mathrm{~V}}$, and transgenic expression of human APP with the Swedish mutation and human $\mathrm{MAPT}^{\mathrm{P} 301 \mathrm{~L}}$ ), has been extensively used to study astrocyte pathology in $\mathrm{AD}$ (see Supplementary Table S2). Astrocytes around A $\beta$ plaques become reactive (increased GFAP levels $[25,160-164]$ and cytokine production $[164,165])$. Nevertheless, such findings only summarize the astrocytic response. Bronzuoli et al. (2019) [160] compared the common astrocyte markers, GFAP, S100 calcium-binding protein B (S100ß), connexin 43 (CX43), and AQP4, in the hippocampi of transgenic and WT mice at 6 months (plaque appearance) and at 12 months of age (NFT appearance). Interestingly, reduced GFAP, S100 $\beta$, CX43, and increased AQP4 protein levels occurred in 12-month-old compared with 6-month-old mice, irrespective of the brain region. This is one of the many studies showing that glial response in $\mathrm{AD}$ varies across brain regions and with age, with the authors opining that there is a complex relation between aging and AD. To gain a better understanding of astrocyte response at single-cell resolution in FAD and the role of aging, more molecularly detailed studies are required (see transcriptomic studies below).

\subsection{Sporadic or Late-Onset Alzheimer's Disease Mouse Models}

Most human AD is of sporadic or late onset on a range of genetically conditioned backgrounds, perhaps involving presently unknown environmental factors. The heritability estimate for LOAD is $60-80 \%$ [8], indicating that genetic predisposition is a major factor for developing this multifactorial disease. As noted, APOE is the major genetic risk factor for developing LOAD [60], with other inflammation-associated genes identified in GWAS databases containing DNA from hundreds of thousands of LOAD subjects. Some of these, notably Apoe and Trem2, have been used to examine the influence on normal brain function. There are other genetically induced LOAD mouse models available (https://www.model-ad.org/strain-table/), but due to space limitations they are not all listed here.

\subsubsection{Apolipoprotein-E Models in Alzheimer's Disease}

APOE is a lipid-associated protein that transports lipids, mostly high-density lipoprotein, between cells and organs [166]. In the CNS, APOE is mainly expressed by astrocytes [167] and is necessary for transport of cholesterol to neurons. The different human APOE alleles $(\varepsilon 2, \varepsilon 3$, and $\varepsilon 4)$ differentially predispose individuals to developing $\mathrm{AD}$ [60] (with $\varepsilon 2$ being protective, while $\varepsilon 4$ increases susceptibility). ApoE mouse models have been made in one of three ways: (1) by knocking out the endogenous mouse Apoe gene to create null mice, (2) by targeted replacement of the mouse Apoe gene with the human $A P O E 2,3$, or 4 allele, or (3) by overexpressing human $A P O E 2,3$, or 4 under a promoter such as GFAP. The substitution of human for mouse is not sufficient to induce astrogliosis, as measured by the number GFAP+ cells in the hippocampus of 4-6-month-old APOE-KI mice compared to Apoe ${ }^{-/-}$mice [168]. The levels of IL-1 $\beta$, IL-6, and TNF- $\alpha$ pro-inflammatory cytokines are also similar among the three strains. This may be due to age, as these mice may have been too young to observe any genotype-related differences, or due to inherent species differences between humans and rodents. For a better understanding of how human $\mathrm{APO} \varepsilon 4$ influences different cell types in the CNS, Tesseur et al. (2000) [58] developed mouse models where APOE4 transgene overexpression was controlled by the mouse Thy1, or by human platelet-derived growth factor (Pdgf), Gfap, or phosphoglycerate kinase ( $P g k$ ) promoters. Neuron-specific transgene overexpression of APOE4 (mouse Thy 1 and human Pdgf promoters) led to an observed increase in the number of GFAP+ astrocytes compared to mice overexpressing human GFAP- and PGK-driven APOE4 and to WT mice ( 8 and 18 months of age). However, the findings in the different mouse lines could have been caused by differential expression levels of APOE4 between the models. For instance, human PGK-APOE4 mice have lower APOE protein levels compared to the other transgenic mice, which could explain the absence of astrogliosis. Additionally, the onset of APOE4 transcription varies by promoter, and since 
cholesterol is involved in brain system development [169], the results could reflect developmental rather than adult functional effects. However, PDGF is active from embryonic day 9.5 (human PDGF promoter sequence was used in the study) and Thy 1 from postnatal day 15 (Table 1 in [58]), suggesting that the observed increase in the number of GFAP+ astrocytes reflects prenatal effects-perhaps an increase in astrocyte proliferation or differentiation. Conclusively, most of the findings in ApoE mouse models point towards a less robust impairment of astrocyte function compared to FAD mouse models. This is in accordance with the consideration of APOE as an AD risk factor. APOE seems to sensitize the brain to developing $\mathrm{AD}$, but there are insufficient data on whether replacement of mouse with human $A P O E$ could lead to AD-like pathology in the carriers.

To better address how the APOE genotype influences astrocytes during $\mathrm{AD}$ development in vivo, ApoE models have been combined with FAD models. The cortical and hippocampal GFAP protein levels, number of GFAP+ astrocytes, and GFAP+ astrocytes per A $\beta$ plaque are reduced in Apoe ${ }^{-/} \times$APPswe/PSEN1dE9 and Gfap-driven Apoe $e^{-/} \times$APPswe/PSEN1dE9 compared to APPswe/PSEN1dE9 mice at 12 months of age [170]. Apoe $e^{-/}$reduces A $\beta$ plaque deposits, and consequently astrogliosis (number of GFAP+ astrocytes) of PDAPP mice overexpressing the APP transgene with the Indiana APP mutation [171]. Thus, the absence of Apoe ameliorates $\mathrm{AD}$-induced astrogliosis. In contrast, human APOE-KI ( $\varepsilon 2, \varepsilon 3$ or $\varepsilon 4)$ in 5 xFAD mice shows prominent astrogliosis in the subiculum and deep cortical layers at 6 months [172], although the effect of each allele on astrocyte activation was not measured. To compare how the APOE genotype influences A $\beta$-induced astrocyte pathology, Dorey et al. (2017) [173] found that protein levels of several cytokines (interferon-gamma (IFN $\gamma$ ), monocyte chemoattractant protein-1 (MCP-1), macrophage inflammatory protein (MIP-1a), Skp/Cullin/F-box containing complex (SCF), Rantes, beta nerve growth factor (b-NGF)) were increased in GFAP-APOE4 (transgenic overexpression) $\times$ APPswe/PSEN1dE9 versus GFAP-APOE2 (transgenic overexpression) $\times$ APPswe/PSEN1dE9 mice at 6 months of age. These results provide additional evidence that $A P O E 4$ sensitizes the brain to developing $\mathrm{AD}$. To gain more functional insight into pathways involved in APOE-induced astrocyte activation in a FAD background, Zheng et al. (2017) [170] measured the protein and mRNA levels of STAT3/STAT3, phospho-STAT3, SMAD2/SMAD2, and phospho-SMAD2 in Apoe $e^{-/-}$and GFAP-driven $A p o e^{-/-} \times$APPswe/PSEN1dE9 compared to APPswe/PSEN1dE9 mice. STAT3 [22,148] and the TGF- $\beta /$ SMAD2 pathway $[22,174]$ are involved in inducing reactive astrogliosis. The ratio of both pSTAT3/STAT3 and pSMAD2/SMAD2 and the TGF- $\beta$ protein levels are reduced in $A p o e^{-/-} \times$APPswe/PSEN1dE9 and Gfap-Apoe $e^{-/} \times$APPswe/PSEN1dE9 compared to APPswe/PSEN1dE9 mice at 12 months of age [170]. Nevertheless, these measurements in both Apoe $^{-/-} \times$APPswe/PSEN1dE9 and Gfap-Apoe ${ }^{-/-} \times$APPswe/PSEN1dE9 models are higher than in WT, suggesting only a partial rescue by knocking out Apoe. The effects of APOE genotype on astrocytes could be related to APOE-driven A $\beta$ uptake from neurons. Perivascular astrocytes, which can clear $\mathrm{A} \beta$ from the brain into the perivascular space, show colocalization with human APOE and A $\beta$ in $\mathrm{APP}^{\mathrm{V} 717 \mathrm{I}} / \mathrm{PSEN} 1{ }^{\mathrm{A} 246 \mathrm{E}}$ mice when the APOE, APP, and PSEN1 transgenes are overexpressed in neurons by the Thy 1 promoter [175]. The astrocytic response to aberrant Tau can also be influenced by the APOE genotype. Similar to APP models, human APOE4-KI astrocytes become reactive by upregulating "A1"-reactive genes in the cortex of 9-month-old human APOE4-KI $\times \mathrm{Tau}^{\mathrm{P} 301 \mathrm{~S}}$ versus Apoe $^{-/-} \times \mathrm{Tau}^{\mathrm{P} 301 \mathrm{~S}}$, further suggesting that APOE worsens AD pathology [176]. The study found a correlation between an elevated hippocampal or piriform GFAP+ area and decreased hippocampal or piriform volume, respectively. It should be noted, however, that this study investigated expression levels of a small subset of genes indicative of only one subtype of reactive astrocytes and that there are likely heterogeneous populations of astrocytes present at the same time, as reported recently in other mouse models of $\mathrm{AD}[31,36]$. Thus, the genetic APOE state (i.e., $\varepsilon 2,3$, or 4 ) seems to be related to the degree of reactive astrogliosis via the classical astrocyte activation pathways in APP mouse models, although additional in vivo evidence regarding the precise astrocytic molecular mechanisms engaged by $\mathrm{A} \beta$ or Tau and the downstream effects is lacking. Once such mechanisms are identified, their presence should be explored in human $\mathrm{AD}$ patients to determine if they are a potential therapeutic target. 


\subsubsection{TREM2 Models in Alzheimer's Disease}

Triggering receptor expressed on myeloid cells-2 (TREM2) is a genetic risk factor for human AD and is expressed by microglia and infiltrating myeloid cells in the CNS [177]. TREM2 ${ }^{-/-}$[178] x PS19 9-month-old mice have reduced Gfap expression and a reduced GFAP-stained area, and the correlation between GFAP- and the IBA1-stained area in the hippocampus is lost compared to PS19 mice, indicating that microglia have an important role in Tau-induced astrogliosis [179]. The expression of Il1a, Il1b, Tnf, C1q, and Apoe in the cortex was also reduced, suggesting that TREM2 aggravates AD pathology. For a more thorough understanding of the effect of Trem $2^{-1-}$, Zhou et al. (2020) [36] performed single nucleus RNA sequencing in 7-month-old Trem $2^{-/-} \times 5 \times F A D$, Trem $2^{-1-}, 5 x F A D$ (expressing APP with the Swedish, Florida, and London mutations and PSEN1 ${ }^{\mathrm{M} 146 \mathrm{~L}, \mathrm{~L} 286 \mathrm{~V}}$ under the control of the mouse Thy1 promoter), and WT mice. The study identified genes that were TREM2-dependent and TREM2-independent of A $\beta$ pathology. Unsurprisingly, given the expression of Trem 2 almost exclusively by microglia, the most robust and significant changes were seen in microglia rather than in neurons or astrocytes (although there were considerable transcriptional changes in oligodendrocytes). Additionally, no robust transcriptional changes were seen in human TREM $2^{R 62 H}$ (a mutation that increases risk for developing AD) astrocytes from AD patients. A more evident effect on astrocytes was observed in human AD samples expressing WT (non-mutated) TREM2, where astrocytes downregulated genes involved in lipid and oxidative metabolism compared to control samples. Given the transcriptomic differences between human AD with WT TREM2 and TREM2R62H, it would be interesting to gain more functional insight on how the background of TREM2 influences astrocyte reactivity in AD. The above paradigms highlight the complexity of AD. TREM2 is a risk factor for developing AD, and microglial pathogenesis and pathology are not entirely dependent on TREM2. The findings between human AD and mouse models attempting to recapitulate AD show some dissimilarities. Additional studies in the future should address how TREM2-dependent and -independent microglia mechanisms influence astrocyte activity in AD and should characterize which FAD models are the most relevant for modeling TREM2-dependent responses in mice.

Both APOE and TREM2 are risk factors for developing LOAD [60-63]. Owing to a focus on genes implicated in FAD (APP, PSENs, MAPT), mouse models with human APOE-targeted replacement and Trem $2^{-/-}$have been less well characterized than FAD models (currently less than 2000 studies in PubMed for APOE and TREM2 compared to over 15,000 studies for APP or Tau mouse models-see Supplementary Information). It seems that a FAD background is necessary to characterize the susceptibility or resistance to AD of LOAD models. Perhaps mutations in multiple risk factor genes are necessary. Even if this is the case, environmental factors that could increase or reduce the onset of AD are not present in mouse studies. For an overview of how AD factors impair normal astrocyte function, see Figure 1. The development of new models will require their proper characterization, and as astrocytes have only recently gained attention in $\mathrm{AD}$ (and in general), there are limited data regarding their behavior under normal and pathological conditions in mice and humans. In the next section, the main limitations of current mouse models will be discussed to provide a better understanding of how to proceed in the future. For an overview of astrocyte findings in LOAD (APOE, TREM2) mouse models, see Supplementary Table S3.

\section{Limitations of Studying Astrocytes in Mouse Models}

\subsection{Limitations Restricted to Astrocytes}

One of the major problems of mouse models is translatability, which is partly explained by differences between human and mouse astrocytes. Recent studies using morphological or transcriptomic comparisons are beginning to characterize the differences $[180,181]$. Such differences could affect AD progression and pathology in each species. For instance, human protoplasmic astrocytes are morphologically more complex and have a higher degree of physical overlap among cells than those of mice [181]. It is possible that the increased overlap could increase Tau seeding or accelerate progression 
of pathology. Furthermore, in humans there is increased astrocyte complexity and increased coverage of multiple neuronal processes per astrocyte (i.e., GFAP+ domain diameter of $142.6 \pm 5.8 \mu \mathrm{m}$ in humans versus $56.0 \pm 2.0 \mu \mathrm{m}$ in mice for protoplasmic astrocytes [181,182]). A $\beta$ pathology leads to astrocytic atrophy away from plaques $[71,73,77,80,183]$, meaning fewer neuronal processes are covered. A testable hypothesis is that astrocytic atrophy is part of a defense designed to minimize seeding of $A \beta$ or Tau aggregates. Despite the presence of atrophic astrocytes prior to disease onset that are hypothesized to lose their function [9], there is no evident impairment in cognition during early AD stages in humans. Perhaps individual astrocytes respond differently to $A \beta$, Tau, and inflammation, and these subpopulations might be different between humans and mice. An example indicating that human and mouse astrocytes respond differently to AD pathology is presented in a single-nucleus RNA sequencing study by Zhou et al. (2020) [36]. A population of astrocytes with high expression of genes involved in lipid and oxidative metabolism under normal conditions was lost in human AD cases, but remained intact in 5xFAD mice. Whether this is due to differences in mouse and human astrocyte responses to pathology or is an artifact of the model is unknown. Additionally, a comparison of mouse and human astrocyte-enriched genes revealed that $52 \%$ of mouse and $30 \%$ of human genes were identically enriched in human and mouse astrocytes, respectively [180]. Whether there are functional differences between human and mouse astrocytes in adults is yet to be determined-although there are examples of similarities $[137,180]$.

Species differences between astrocytes from humans and mice may limit the translatability of some findings. The best example is the expression of Toll-like receptors (TLRs). TLRs are activated by pathogens or danger-associated molecular patterns (DAMPs), including $A \beta$ [44], triggering an inflammatory response $[184,185]$. TLRs are expressed in all cell types in the CNS, although different family members may be differentially expressed in different cells [186]. As inflammation plays an important role in AD, so do TLRs (for a review see [186]). Many studies on TLRs and inflammation have been done in mice, however the members and level of expression of each receptor varies between mouse and human CNS cells. For instance, human astrocytes express Tlr1-6 and Tlr9, whereas mouse astrocytes express Tlrs at low levels or not at all $[65,180,186]$. Additionally, the recognition pattern for bacteria between TLR9 in mice and humans differs [187]. Thus, the genetic differences of mice compared to humans can explain why there is a lack of translatability. Currently, other models based on a wider number of mouse backgrounds (https://www.model-ad.org/strain-table/) and human-induced pluripotent stem cell (hIPSC) culture models ([188-190] among others) are being used and developed to better understand human AD pathology.

\subsection{Other Limitations of Studying AD in Mice}

Aging is the major risk factor for contracting AD [191]. Mouse and human transcriptomic studies have characterized age-related changes in the brain [149,192,193]. Furthermore, each AD mouse model develops the pathology at a different age (for an overview visit https://www.alzforum.org/researchmodels/alzheimers-disease). Thus, the interaction with aging contributes differently to each transgenic or knock-in mouse line, adding another level of complexity. The mouse genome and aging are not sufficient for AD to naturally occur in mice. Directly comparing aging between different organisms may also be complicated due to species-specific differences. These original species comparisons of astrocyte transcriptomes were done using non-comparable brain regions, so they may represent regional differences as well as species differences. Additional studies report some similarities in transcriptomic changes in mouse and human CNS cells with age $[149,192,193]$. Perhaps comparing such studies can help pinpoint differences between mouse and human aging and identify which mouse models most closely resemble the time point of AD onset in humans.

Apart from these core limitations, there are others that deserve attention. More women suffer from AD than men, and AD mouse models show sex-related differences in plaque load and NFT pathology $[86,87]$. The use of both sexes interchangeably (or in combination) in the past has restricted our understanding of AD vulnerability between sexes. Furthermore, the number of males to females 
in each experimental group was not always mentioned, rendering comparisons among or between studies difficult.

Housing imposes another variable that must be controlled for when using mouse models. To reduce inter-individual variability, mice are bred in a controlled environment. These controlled environments remove exposure to environmental factors-these are known to alter the gut microbiome, which can robustly change the pathogenesis of some APP transgenic mouse models [194-196]. Similarly, gut bacterial flora can interact with the inflammatory system, which consequently led to astrocyte and microglia changes in an experimental autoimmune encephalomyelitis model [197]. Since gut microbiota seem to play a role in AD development $[91,198]$, it is possible that environmental factors affect the results and could account for discrepancies between laboratories. The recently advanced notion that $\mathrm{A} \beta$ behaves similarly to a microbial defense mechanism makes these considerations even more relevant [199].

Importantly, the mice themselves are inbred, meaning that genotype differences between mice are kept to a minimum [200]. While this approach ensures findings and treatment effects can be reproduced between laboratories, the human population consists of high genetic variability. Any treatment developed in the context of a single mouse model might only be relevant for a specific population of humans. On the other hand, effects seen in mice might not be observable in humans due to the individuals selected and the genetic differences between humans and mice. Similarly, mouse models with different APP mutations show different findings (e.g., in AQP4 [40,98,101,201]). These differences might be a model artifact or could be mutation-related and represent the different vulnerability of individuals to developing $\mathrm{AD}$ (affected by components or pathways).

Combined, age, sex, and microbiome present additional complications that have not been fully recognized with respect to astrocyte responses in diseases such as AD. These variables are now being acknowledged with respect to our full understanding of the heterogeneous and context-dependent responses of all glial and immune cells to disease, infection, and injury.

\section{Recent Studies and Future Perspectives for Studying Astrocytes in AD}

\subsection{Transcriptomic Studies}

As mentioned above, human and mouse astrocytes have similarities, but also important transcriptomic differences. The heterogeneity is also present within a single species. Hippocampal astrocytes differ from cortical astrocytes in their morphology, transcriptome, proteome, electrophysiology, and $\mathrm{Ca}^{2+}$ signaling [126]. Morphological differences between astrocytes in different cortical layers in the mouse suggest subregional heterogeneity [105], which has been confirmed transcriptomically in both mice and humans [127]. High-throughput in situ hybridization shows both layer-dependent and -independent heterogeneity. Additionally, not only do astrocyte transcriptomes differ spatially (between and within different brain regions), but also temporally (throughout aging) $[149,193]$. Studies that are designed to identify the extent to which various astrocyte sub-states are predetermined or locally plastic, as determined by their anatomic or functional niche, and how aging affects each sub-state would shed even more light on our understanding of selective vulnerability in AD. Such information could also be used to identify mechanisms of resistance that might be enhanced therapeutically to arrest or reverse the pathology.

Whereas these studies focus on astrocytes under normal conditions, it should be noted that transcriptomics are also used to decipher astrocyte response in disease contexts, including for AD. Habib et al. (2020) [31] identified a population of astrocytes with a unique transcriptomic signature (termed disease-associated astrocytes-DAAs) appearing at 4 months of age in 5xFAD mice. This population was found in WT animals from 13 months of age, but even at 20 months of age the number of DAAs was minimal compared to 7-month-old 5xFAD mice. DAAs express high levels of Gfap but have different enriched pathways compared to high-expressing Gfap astrocytes present in normal conditions. The lysosomal, inflammatory response, and complement pathways are few of the DAA-only enriched pathways in 5xFAD mice. Furthermore, the expression profile of DAAs 
partially matches the pan-reactive and A1-reactive profile of astrocytes in the Zamanian et al. (2012) [29] and Liddelow et al. (2017) [30]. It would be interesting to see whether DAAs are associated with plaque pathology or if they are present in human patients. Chen et al. (2020) [32] conducted spatial transcriptomic analysis and in situ sequencing in APP ${ }^{N L-G-F}$ mice, comparing not only the genotype $\left(\mathrm{APP} \mathrm{NL-G}^{\mathrm{F}}\right.$ or WT), but also the effect of A $\beta$ plaques on gene expression. The most differentially expressed genes in both categories were grouped and termed plague-induced genes (PIGs). PIGs are mostly enriched in microglia and to a lesser degree in astrocytes. Interestingly, as the disease progresses and $\mathrm{A} \beta$ accumulates, the network connectivity of microglial and astrocytic genes increases. For example, astrocytic cathepsin D, a lysosomal protease whose gene expression is deregulated in AD [202-204], forms strong connections with microglial complement pathway components C1qa and $C 1 q b$, which are involved in astrocyte reactivity induction [30]. Astrocytic ApoE also forms strong connections with microglial $C 1 q b$ [32]. ApoE binding to $C 1 q$ near $A \beta$ plaques leads to inhibition of the complement cascade and correlates with cognitive decline [205]. Additional functional studies are necessary to identify how AD-related genes, which were characterized in various transcriptomic studies, interact during disease progression and whether they could be targeted for treatment.

In different astrocyte transcriptomic studies in $\mathrm{AD}$ mouse models, researchers have compared the astrocytic expression to the A1- or A2-reactive astrocyte profile [31-33]. However, only a partial similarity was observed. Additionally, the signatures of A1- and A2-reactive astrocytes have not been validated in human AD brains or genetically induced AD mouse models. Das et al. (2017) [206] performed a meta-analysis of mouse astrocyte transcriptomes in acute injury and neurodegenerative disease mouse models, including the APPswe/PSEN1dE9, PS2APP, and PS19 AD mouse models. They found that whether an astrocyte will acquire an A1 or A2 transcriptomic phenotype is not specific to the disease's nature (acute injury versus neurodegeneration). Rather, genes from each category are upregulated in each disease. This further suggests summarizing the astrocyte response into A1- or A2-reactive could lead to data misinterpretation. This does not mean there are not distinct astrocyte transcriptome signatures between different diseases. For instance, mouse models of acute CNS injury display different transcriptome profiles to mouse models of neurodegeneration. It is highly likely that such a heterogeneity is present between different models of acute injury or neurodegeneration (i.e., Alzheimer's disease, Parkinson's disease, amyotrophic lateral sclerosis), yet further studies are necessary to validate this. Conclusively, astrocyte transcriptomic analyses in AD mouse models are a powerful tool for pinpointing genes and pathways involved in the disease progression, but care should be taken when extrapolating the results to humans (see [206]). The above studies reported astrocyte heterogeneity within a few brain regions, while Wang et al. (2016) [207] performed a transcriptomic network analysis of 19 human brain regions, comparing AD and control patients. The study highlights differentially expressed genes per brain region with AD pathological traits-including cognitive deficits, A $\beta$ plaques, and NFT pathology. Of these regions, 17 had modules enriched for inflammatory responses-a common response of astrocytes in many neurodegenerative diseases and infections ([30,149,176,208,209], among others). If inflammation is commonly induced in many brain regions, why do some cortical regions and the hippocampus develop AD pathology first? Is it due to the differential expression of inflammatory genes between brain regions or the contribution of other pathways such as lipid homeostasis (see [193]) (or both) that explain this vulnerability? To what extent does brain area connectivity contribute to spatial vulnerability? The heterogeneity in astrocyte responses-across brain regions, throughout development, and with respect to the initiating stimuli-may explain the selective vulnerability of different brain regions to developing diseases such as $\mathrm{AD}$. Some possibilities are supported with more evidence than others, but in the end integration of (new) transcriptomic studies with other already published datasets can provide a basis for forming new hypotheses to study how cellular-in our case astrocytic-homeostasis is impaired in AD. These studies will provide a better understanding of not only disease pathology, but also whether there is a common mechanism in AD that could be targeted for treatment. 


\subsection{The Rise of Proteomics}

While transcriptomics have become relatively more accessible, their lowered costs still remain beyond the means of many groups. Proteomic studies might capture additional pathways that are activated by post-translational mechanisms and do not require changes in transcription. Using mass spectrometry (MS)-based proteomics in human samples of the dorso-lateral prefrontal cortex with or without AD, Johnson et al. (2020) [210] generated an AD brain coexpression network to pinpoint pathways and cell-type-specific changes. The study correlated protein levels with $\mathrm{A} \beta$ plaques, NFTs, and cognitive functions to identify relationships independent of $A \beta$ and NFTs. One of the most significantly altered biological functions involved glucose and carbohydrate metabolism. This module consisted of astrocytes and microglia, which upregulated several anti-inflammatory genes (i.e., Fabp5 Spp1, Lmnb1), although a few pro-inflammatory genes were also identified (i.e., Tspo, Iqgap1, Nampt). Microglial proteins highly present in AD samples were involved in anti-inflammatory response, while astrocyte markers included both A1- and A2-reactive gene products. As in AD, normal aging brains showed an increase in the levels of proteins involved in glucose and carbohydrate metabolism. However, other modules were differentially affected, implying a complex relationship between aging and $\mathrm{AD}$ at the protein level. The study is limited to the dorso-lateral prefrontal cortex. In the future, more brain areas should be analyzed using proteomics to gain a better understanding of region vulnerability in $\mathrm{AD}$, which could also help target potential pathways for treatment.

Proteomics has also been used to study the cerebrospinal fluid (CSF) for biomarkers with possible clinical or pathogenetic significance [210,211]. Glucose and carbohydrate metabolism pathway-related proteins were enriched in the CSF of $\mathrm{AD}$ patients, with increasing levels observed in asymptomatic $\mathrm{AD}$ patients for some of these proteins [210]. Future studies should test whether the pathway of glucose and carbohydrate metabolism is similarly affected in other brain regions. Additionally, they should also validate the extent to which the findings reproduce the results of transcriptomic studies. Currently, single-cell proteomics studies have addressed human microglia heterogeneity [212], and perhaps similar data regarding CNS cells, including astrocytes, in AD will be helpful towards our understanding of this disease.

Transcriptomics and proteomics provide great tools that can be used to identify novel pathways and biological processes in $\mathrm{AD}$, but the findings should be validated by functional studies. In vitro cultures and in vivo mouse models are still necessary to understand astrocyte function in a simple cellular model (in vitro) and in a model with the complexity of a living organism (mice and other animal models [213]).

\subsection{Novel Mouse Models}

As most $\mathrm{AD}$ is sporadic, and many recent studies have identified genetic loci implicated in human LOAD, relevant mouse models for LOAD using these genes are being developed in the context of the Model Organism Development and Evaluation for Late-Onset Alzheimer's Disease (MODEL-AD) consortium (https://www.model-ad.org/). This project is tasked with creating novel in vivo mouse models for LOAD [46]. It is hoped that the use of multiple mouse strains will provide genetic diversity that is more similar to that in human patients [213]. For example, it is known that C57BL/6J appears to be resistant to AD and similar neuropathologies, however the mechanism is unknown. The long-term goal of MODEL-AD is to characterize such models, defining features that correspond to stages of the human disease in order to discover biomarkers related to pathogenesis that can be used in drug development and clinical testing. MODEL-AD attempts to overcome the problems intrinsic to the prior models, which are based on the role of $A \beta$ in pathogenesis. It must be noted that since LOAD and FAD have been defined by the presence of plaques and tangles, it may be difficult to produce those pathologies in the absence of human AD-associated transgenes. Similarly, models based on the administration of streptozotocin intracerebrally, or of LPS systemically or intracerebrally, while reproducing many of the inflammatory features of $\mathrm{AD}$ and other neurodegenerative diseases, have only minimal increases 
in $\mathrm{A} \beta$ (plaques) or Tau aggregation (tangles). This makes them difficult to interpret in the context of human LOAD, which shows both.

Currently, there are no data describing astrocyte function in MODEL-AD mouse models. Presumably, after standardization and extensive characterization of mouse models, such studies will shed light on the role of astrocytes in LOAD. Since multiple genetic loci are implicated in LOAD, different models should provide evidence of the different aspects of astrocytes in AD pathophysiology. Additionally, mixing these models could further contribute to how different genes and cellular pathways might induce abnormal astrocyte function in LOAD. While no mouse model will be able to recapitulate all aspects of astrocyte function (or dysfunction) associated with $A D$, proper characterization of the transcriptomic, proteomic, and functional changes present in current and future models and comparisons with human data are required. Animal models will remain necessary to understand AD pathology and astrocyte function, particularly in vivo [214].

\subsection{Chimeric Mice}

Mice are genetically different to humans, which often limits the translatability of AD mouse models. To partially overcome this, chimeric mice, whereby human glial progenitor cells (hGPCs) are engrafted in the mouse brain, can be used (Figure 2). Indeed, the hGPCs engrafted in the neonatal mouse brain can expand and differentiate into astrocytes and oligodendrocytes [182]. In Shiverer mice, which display hypomyelination, human glia replaced the host population within a year [182]. These mice ought to help us understand how human glia contribute to neurodegenerative disorders. The chimeric glia mouse brain usefulness and limitations in studying the glial role in human pathology have already been reviewed [215]. So far, such chimeric mice were used to identify the glial role in Huntington's disease [216] and childhood schizophrenia [217]. Other than understanding their pathogenic role in neurodegeneration, chimeric mice could be used to understand how human astrocytes contribute to increased cognition. Han et al. (2013) [218] engrafted hGPCs into neonatal mice, which showed improved synaptic plasticity and learning. The differences between mouse and human astrocytes in the mouse brain could perhaps help identify potential reasons why mice do not develop AD. Other potential uses of chimeric mice include engraftment of hGPCs carrying FAD mutations. The mutation could occur naturally and represent the natural variability of human $\mathrm{AD}$ or could be induced by mutagenesis to ensure an isogenic background between mutated and control lines. For LOAD, APO $\varepsilon 4$ or $\varepsilon 3 \mathrm{hGPCs}$ could be used. Of course, other genes implicated as risk factors for LOAD can be studied. Since hGPCs require human fetuses, it would be helpful to develop a protocol for grafting hIPSC-derived hGPCs in mouse brains. The field of study for chimeric mice is relatively new and is believed to provide crucial information of human astrocyte (and glial in general) contributions to $\mathrm{AD}$, as well as possibly describing ways to improve translatability. 


\section{Established methods for studying AD}
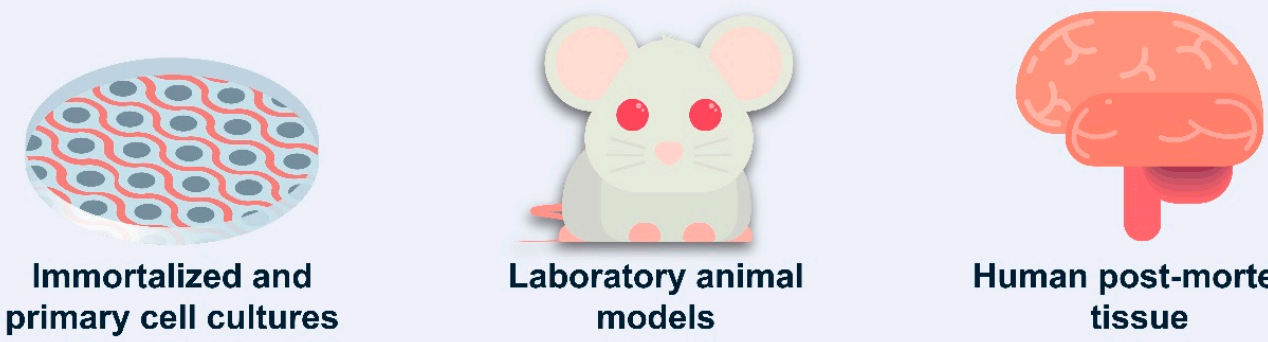

Human post-mortem tissue

\section{New methods for studying AD}

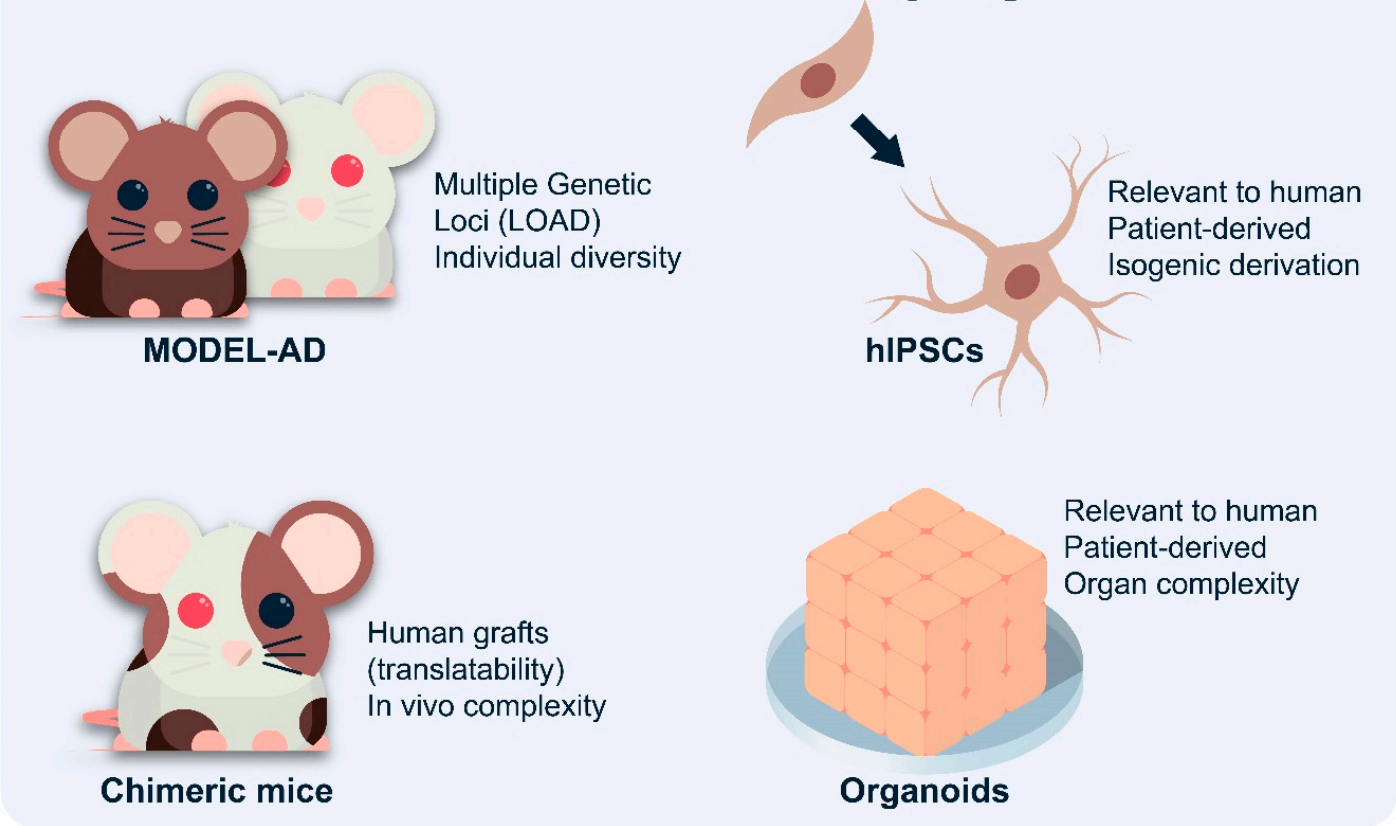

Figure 2. Overview of established and novel methodologies and models used to study Alzheimer's disease. Top: various in vitro and in vivo models have been generated over the past years and are being used along with human tissue to study AD. Bottom: four new methodologies and models that have been developed in the past few years to improve the translatability and relevance of findings for AD. The MODEL-AD consortium will increase the availability of mouse models carrying different mutations and will include wild mouse strains that represent the genetic diversity present in human patients. Human-induced pluripotent stem cells that can be differentiated to a specific cell type (i.e., astrocytes) or organoids are in vitro models with a human genetic background and can be specific for each patient. Chimeric mice where hIPSCs or human differentiated cells can be engrafted in an in vivo model can combine the advantages of a living organism - in this case a mouse-and human in vitro models. Note that for the new methodologies, the main advantages for AD are mentioned, but there are also major drawbacks. For additional information on the models for studying brain disease, the reader can refer to specific reviews (MODEL-AD (https://www.model-ad.org/), hIPSCs [219-221], organoids [136], chimeric mice [215]). Abbreviations: $\mathrm{AD}=$ Alzheimer's disease; hIPCS = human-induced pluripotent stem cells; LOAD = late-onset Alzheimer's disease; MODEL-AD = Model Organism Development and Evaluation for Late-Onset Alzheimer's Disease.

\section{Conclusions}

As $\mathrm{AD}$ is a multifactorial disease, it is imperative to understand how different components contribute to disease pathogenesis in both humans and in rodent models. One major consideration 
is the differential contribution of each of the various cell types present in the CNS. Current models have helped us understand AD pathology, particularly in terms of neuronal dysfunction and synaptic loss, yet we still do not fully understand the role of astrocytes. To improve translatability, new models need to be developed that more accurately recapitulate the changes seen in human patients-and these initial steps have already been taken. Chimeric mice combine advantages from both hiPSCs and mouse models, while the MODEL-AD consortium has the potential to provide addition rodent models that incorporate complex and mixed background strains that could help our understanding of the disease and find ways to cure it. The new models provide a vast range of opportunities to design novel approaches to understand AD. The next decade will prove to be exciting in the field of neurodegeneration, including new insights into the role of astrocytes. How do astrocytes become reactive in $\mathrm{AD}$, and what are the exact molecular mechanisms? Are such mechanisms preserved between different brain regions? How many different reactive states are there? If multiple reactive states are present, which ones play protective roles and which ones contribute to the pathology? What are the differences between mouse and human astrocytes under normal or pathological conditions? We are beginning to understand the complexity and context-dependent nature of heterogeneous astrocyte responses in many disease and infection models.

Supplementary Materials: The following are available online at http:/www.mdpi.com/2073-4409/9/11/2415/s1, Overview of literature search parameters. Table S1: Main astrocytic findings from APP and PSEN mouse models. Table S2: Main astrocytic findings from Tau mouse models: MAPT and APP/MAPT/PSEN (3xTg). Table S3: Main astrocytic findings from LOAD and LOAD/FAD mouse models. Supplementary References.

Author Contributions: F.S. and S.A.L. wrote the manuscript. All authors have read and agreed to the published version of the manuscript.

Funding: We acknowledge the support of the Cure Alzheimer's Fund and Blas Frangione Foundation to S.A.L.

Acknowledgments: We would like to thank Joel Buxbaum and Jessica Sadick for careful review and comments on the manuscript.

Conflicts of Interest: The funders had no role in the design of the study; in the collection, analyses, or interpretation of data; in the writing of the manuscript, or in the decision to publish the results. S.A.L. is an academic founder of AstronauTx Ltd.

\section{References}

1. Jahn, H. Memory loss in Alzheimer's disease. Clin. Res. 2013, 15, 445-454.

2. Haj, M. El Memory suppression in Alzheimer's disease. Neurol. Sci. 2016, 37, 337-343. [CrossRef]

3. Bondi, M.W.; Edmonds, E.C.; Salmon, D.P. Alzheimer's Disease: Past, Present, and Future. J. Int. Neuropsychol. Soc. 2017, 23, 818-831. [CrossRef] [PubMed]

4. Serrano-Pozo, A.; Frosch, M.P.; Masliah, E.; Hyman, B.T. Neuropathological Alterations in Alzheimer Disease. Cold Sping Harb. Perspect. Med. 2011, 1, 1-23. [CrossRef] [PubMed]

5. O'Brien, R.J.; Wong, P.C. Amyloid Precursor Protein Processing in Alzheimer's Disease. Annu. Rev. Neurosci. 2011, 34, 185-204. [CrossRef]

6. Cummings, J.L.; Morstorf, T.; Zhong, K. Alzheimer's disease drug-development pipeline: Few candidates, frequent failures. Alzheimers Res. Ther. 2014, 6. [CrossRef] [PubMed]

7. Gauthier, S.; Albert, M.; Fox, N.; Goedert, M.; Kivipelto, M.; Mestre-Ferrandiz, J.; Middleton, L.T. Why has therapy development for dementia failed in the last two decades? Alzheimers Dement. 2016, 12, 60-64. [CrossRef]

8. Gatz, M.; Reynolds, C.A.; Fratiglioni, L.; Johansson, B.; Mortimer, J.A.; Berg, S.; Fiske, A.; Pedersen, N.L. Role of genes and environments for explaining Alzheimer disease. Arch. Gen. Psychiatry 2006, 63, 168-174. [CrossRef]

9. Arranz, A.M.; De Strooper, B. The role of astroglia in Alzheimer's disease: Pathophysiology and clinical implications. Lancet Glob. Health 2019, 4422, 25-27. [CrossRef]

10. Sadick, J.S.; Liddelow, S.A. Don't forget astrocytes when targeting Alzheimer's disease. Br. J. Pharmacol. 2019, 176, 3585-3598. [CrossRef] [PubMed] 
11. Bennett, F.C.; Liddelow, S.A. Microglia Metabolic Breakdown Drives Alzheimer's Pathology. Cell Metab. 2019, 30, 405-406. [CrossRef] [PubMed]

12. Nortley, R.; Korte, N.; Izquierdo, P.; Hirunpattarasilp, C.; Mishra, A.; Jaunmuktane, Z.; Kyrargyri, V.; Pfeiffer, T.; Khennouf, L.; Madry, C.; et al. Amyloid $\beta$ oligomers constrict human capillaries in Alzheimer's disease via signaling to pericytes. Science 2019, 365. [CrossRef] [PubMed]

13. Von Bartheld, C.S.; Bahney, J.; Herculano-Houzel, S. The Search for True Numbers of Neurons and Glial Cells in the Human Brain: A Review of 150 Years of Cell Counting. J. Comp. Neurol. 2016, 524, 3865-3895. [CrossRef] [PubMed]

14. Erö, C.; Gewaltig, M.O.; Keller, D.; Markram, H. A cell atlas for the mouse brain. Front. Neuroinform. 2018, 12, 1-16. [CrossRef]

15. Keller, D.; Erö, C.; Markram, H. Cell densities in the mouse brain: A systematic review. Front. Neuroanat. 2018, 12. [CrossRef] [PubMed]

16. Pelvig, D.P.; Pakkenberg, H.; Stark, A.K.; Pakkenberg, B. Neocortical glial cell numbers in human brains. Neurobiol. Aging 2008, 29, 1754-1762. [CrossRef]

17. Allen, N.J. Astrocyte Regulation of Synaptic Behavior. Annu. Rev. Cell Dev. Biol. 2014, 30, 439-463. [CrossRef]

18. Mahmoud, S.; Gharagozloo, M.; Simard, C.; Gris, D. Astrocytes Maintain Glutamate Homeostasis in the CNS by Controlling the Balance between Glutamate Uptake and Release. Cells 2019, 8, 184. [CrossRef]

19. Barreto, G.E.; Gonzalez, J.; Torres, Y.; Morales, L. Astrocytic-neuronal crosstalk: Implications for neuroprotection from brain injury. Neurosci. Res. 2011, 71, 107-113. [CrossRef] [PubMed]

20. Liu, C.; Yang, Y.; Ju, W.; Wang, X.; Zhang, H. Emerging Roles of Astrocytes in Neuro-Vascular Unit and the Tripartite Synapse with Emphasis on Reactive Gliosis in the Context of Alzheimer's Disease. Front. Cell. Neurosci. 2018, 12, 1-12. [CrossRef]

21. Macvicar, B.A.; Newman, E.A. Astrocyte Regulation of Blood Flow in the Brain. Cold Sping Harb. Perspect. Med. 2015, 7, 1-14. [CrossRef]

22. Sofroniew, M.V. Astrogliosis. Cold Spring Harb. Perspect. Biol. 2015, 7, 1-16. [CrossRef] [PubMed]

23. Liddelow, S.A.; Barres, B.A. Reactive Astrocytes: Production, Function, and Therapeutic Potential. Immunity 2017, 46, 957-967. [CrossRef] [PubMed]

24. Bignami, A.; Eng, L.F.; Dahl, D.; Uyeda, C.T. Localization of the glial fibrillary acidic protein in astrocytes by immunofluorescence. Brain Res. 1972, 43, 429-435. [CrossRef]

25. Alberdi, E.; Wyssenbach, A.; Alberdi, M.; Sánchez-Gómez, M.V.; Cavaliere, F.; Rodríguez, J.J.; Verkhratsky, A.; Matute, C. Calcium-dependent endoplasmic reticulum stress correlates with astrogliosis in oligomeric amyloid $\beta$-treated astrocytes and in a model of Alzheimer's disease. Aging Cell 2013, 12, 292-302. [CrossRef]

26. Doméné, A.; Cavanagh, C.; Page, G.; Bodard, S.; Klein, C.; Delarasse, C.; Chalon, S.; Krantic, S. Expression of Phenotypic Astrocyte Marker Is Increased in a Transgenic Mouse Model of Alzheimer's Disease versus Age-Matched Controls: A Presymptomatic Stage Study. Int. J. Alzheimers Dis. 2016. [CrossRef]

27. Li, K.; Li, J.; Zheng, J.; Qin, S. Reactive Astrocytes in Neurodegenerative Diseases. Aging Dis. 2019, 10, 664-675. [CrossRef]

28. Porchet, R.; Probst, A.; Bouras, C.; Dráberová, E.; Dráber, P.; Riederer, B.M. Analysis of gial acidic fibrillary protein in the human entorhinal cortex during aging and in Alzheimer's disease. Proteomics 2003, 3, 1476-1485. [CrossRef]

29. Zamanian, J.L.; Xu, L.; Foo, L.C.; Nouri, N.; Zhou, L.; Giffard, R.G.; Barres, B.A. Genomic analysis of reactive astrogliosis. J. Neurosci. 2012, 32, 6391-6410. [CrossRef]

30. Liddelow, S.A.; Guttenplan, K.A.; Clarke, L.E.; Bennett, F.C.; Bohlen, C.J.; Schirmer, L.; Bennett, M.L.; Münch, A.E.; Chung, W.S.; Peterson, T.C.; et al. Neurotoxic reactive astrocytes are induced by activated microglia. Nature 2017, 541, 481-487. [CrossRef]

31. Habib, N.; McCabe, C.; Medina, S.; Varshavsky, M.; Kitsberg, D.; Dvir-Szternfeld, R.; Green, G.; Dionne, D.; Nguyen, L.; Marshall, J.L.; et al. Disease-associated astrocytes in Alzheimer's disease and aging. Nat. Neurosci. 2020, 23, 701-706. [CrossRef]

32. Chen, W.T.; Lu, A.; Craessaerts, K.; Pavie, B.; Sala Frigerio, C.; Corthout, N.; Qian, X.; Laláková, J.; Kühnemund, M.; Voytyuk, I.; et al. Spatial Transcriptomics and In Situ Sequencing to Study Alzheimer's Disease. Cell 2020, 182, 976-991.e19. [CrossRef] 
33. Wu, T.; Dejanovic, B.; Gandham, V.D.; Gogineni, A.; Edmonds, R.; Schauer, S.; Srinivasan, K.; Huntley, M.A.; Wang, Y.; Wang, T.M.; et al. Complement C3 Is Activated in Human AD Brain and Is Required for Neurodegeneration in Mouse Models of Amyloidosis and Tauopathy. Cell Rep. 2019, 28, 2111-2123.e6. [CrossRef]

34. Chen, W.T.; Lu, A.; Craessaerts, K.; Pavie, B.; Frigerio, C.S.; Mancuso, R.; Qian, X.; Lalakova, J.; Kühnemund, M.; Voytyuk, I.; et al. Spatial and temporal transcriptomics reveal microglia-astroglia crosstalk in the amyloid- $\beta$ plaque cell niche of Alzheimer's disease. bioRxiv 2019, 719930. [CrossRef]

35. Mathys, H.; Davila-Velderrain, J.; Peng, Z.; Gao, F.; Mohammadi, S.; Young, J.Z.; Menon, M.; He, L.; Abdurrob, F.; Jiang, X.; et al. Single-cell transcriptomic analysis of Alzheimer's disease. Nature 2019, 570, 332-337. [CrossRef]

36. Zhou, Y.; Song, W.M.; Andhey, P.S.; Swain, A.; Levy, T.; Miller, K.R.; Poliani, P.L.; Cominelli, M.; Grover, S.; Gilfillan, S.; et al. Human and mouse single-nucleus transcriptomics reveal TREM2-dependent and TREM2-independent cellular responses in Alzheimer's disease. Nat. Med. 2020, 26, 131-142. [CrossRef]

37. Grubman, A.; Chew, G.; Ouyang, J.F.; Sun, G.; Choo, X.Y.; McLean, C.; Simmons, R.K.; Buckberry, S.; Vargas-Landin, D.B.; Poppe, D.; et al. A single-cell atlas of entorhinal cortex from individuals with Alzheimer's disease reveals cell-type-specific gene expression regulation. Nat. Neurosci. 2019, 22, 2087-2097. [CrossRef]

38. Liddelow, S.A.; Marsh, S.E.; Stevens, B. Microglia and astrocyte interactions in health and disease: Dynamic Duo or Partners in Crime? Trends Immunol. 2020, 41, 820-835. [CrossRef]

39. Delekate, A.; Füchtemeier, M.; Schumacher, T.; Ulbrich, C.; Foddis, M.; Petzold, G.C. Metabotropic P2Y1 receptor signalling mediates astrocytic hyperactivity in vivo in an Alzheimer's disease mouse model. Nat. Commun. 2014, 5. [CrossRef] [PubMed]

40. Yang, J.; Zhang, R.; Shi, C.; Mao, C.; Yang, Z.; Suo, Z.; Torp, R.; Xu, Y. AQP4 Association with Amyloid Deposition and Astrocyte Pathology in the Tg-ArcSwe Mouse Model of Alzheimer's Disease. J. Alzheimers Dis. 2011, 27, 622-711. [CrossRef]

41. Balducci, C.; Forloni, G. APP Transgenic Mice: Their Use and Limitations. Neuromol. Med. 2011, 13, $117-137$. [CrossRef] [PubMed]

42. Herrup, K.; Carrillo, M.C.; Schenk, D.; Cacace, A.; Desanti, S.; Fremeau, R.; Bhat, R.; Glicksman, M.; May, P.; Swerdlow, R.; et al. Beyond amyloid: Getting real about nonamyloid targets in Alzheimer's disease. Alzheimers Dement. 2013, 9, 452-458. [CrossRef]

43. Kitazawa, M.; Medeiros, R.; Laferla, F.M. Transgenic Mouse Models of Alzheimer Disease: Developing a Better Model as a Tool for Therapeutic Interventions. Curr. Pharm. Des. 2012, 18, 1131-1147. [CrossRef] [PubMed]

44. Heneka, M.T.; Carson, M.J.; El Khoury, J.; Landreth, G.E.; Brosseron, F.; Feinstein, D.L.; Jacobs, A.H.; Wyss-Coray, T.; Vitorica, J.; Ransohoff, R.M.; et al. Neuroinflammation in Alzheimer's disease. Lancet Neurol. 2015, 14, 388-405. [CrossRef]

45. Govindpani, K.; McNamara, L.G.; Smith, N.R.; Vinnakota, C.; Waldvogel, H.J.; Faull, R.L.; Kwakowsky, A. Vascular Dysfunction in Alzheimer's Disease: A Prelude to the Pathological Process or a Consequence of It? J. Clin. Med. 2019, 8, 651. [CrossRef] [PubMed]

46. Onos, K.D.; Uyar, A.; Keezer, K.J.; Jackson, H.M.; Preuss, C.; Acklin, C.J.; O’Rourke, R.; Buchanan, R.; Cossette, T.L.; Sukoff Rizzo, S.J.; et al. Enhancing face validity of mouse models of Alzheimer's disease with natural genetic variation. PLoS Genet. 2019, 15, e1008155. [CrossRef]

47. Neuner, S.M.; Heuer, S.E.; Huentelman, M.J.; O'Connell, K.M.S.; Kaczorowski, C.C. Harnessing Genetic Complexity to Enhance Translatability of Alzheimer's Disease Mouse Models: A Path toward Precision Medicine. Neuron 2019, 101, 399-411.e5. [CrossRef]

48. Dunn, A.R.; O'Connell, K.M.S.; Kaczorowski, C.C. Gene-by-environment interactions in Alzheimer's disease and Parkinson's disease. Neurosci. Biobehav. Rev. 2019, 103, 73-80. [CrossRef]

49. Wang, H.; Li, Y.; Ryder, J.W.; Hole, J.T.; Ebert, P.J.; Airey, D.C.; Qian, H.R.; Logsdon, B.; Fisher, A.; Ahmed, Z.; et al. Genome-wide RNAseq study of the molecular mechanisms underlying microglia activation in response to pathological tau perturbation in the rTg4510 tau transgenic animal model. Mol. Neurodegener. 2018, 13, 1-19. [CrossRef]

50. Mukherjee, S.; Perumal, T.M.; Daily, K.; Sieberts, S.K.; Omberg, L.; Preuss, C.; Carter, G.W.; Mangravite, L.M.; Logsdon, B.A. Identifying and ranking potential driver genes of Alzheimer's disease using multiview evidence aggregation. Bioinformatics 2019, 35, i568-i576. [CrossRef]

51. Wan, Y.W.; Al-Ouran, R.; Mangleburg, C.G.; Perumal, T.M.; Lee, T.V.; Allison, K.; Swarup, V.; Funk, C.C.; Gaiteri, C.; Allen, M.; et al. Meta-Analysis of the Alzheimer's Disease Human Brain Transcriptome and Functional Dissection in Mouse Models. Cell Rep. 2020, 32. [CrossRef] [PubMed] 
52. Elder, G.A.; Gama Sosa, M.A.; De Gasperi, R. Transgenic Mouse Models of Alzheimer's Disease. Mt. Sinai J. Med. 2010, 77, 68-81. [CrossRef]

53. Hall, A.M.; Roberson, E.D. Mouse models of Alzheimer's disease. Brain Res. Bull. 2012, 88, 3-12. [CrossRef]

54. Sturchler-Pierrat, C.; Abramowski, D.; Duke, M.; Wiederhold, K.H.; Mistl, C.; Rothacher, S.; Ledermann, B.; Bürki, K.; Frey, P.; Paganetti, P.A.; et al. Two amyloid precursor protein transgenic mouse models with Alzheimer disease-like pathology. Proc. Natl. Acad. Sci. USA 1997, 94, 13287-13292. [CrossRef] [PubMed]

55. Dujardin, S.; Colin, M.; Buée, L. Invited review: Animal models of tauopathies and their implications for research/translation into the clinic. Neuropathol. Appl. Neurobiol. 2015, 41, 59-80. [CrossRef] [PubMed]

56. Jackson, R.J.; Rudinskiy, N.; Herrmann, A.G.; Croft, S.; Kim, J.S.M.; Petrova, V.; Ramos-Rodriguez, J.J.; Pitstick, R.; Wegmann, S.; Garcia-Alloza, M.; et al. Human tau increases amyloid $\beta$ plaque size but not amyloid $\beta$-mediated synapse loss in a novel mouse model of Alzheimer's disease. Eur. J. Neurosci. 2016, 44, 3056-3066. [CrossRef]

57. Oddo, S.; Caccamo, A.; Shepherd, J.D.; Murphy, M.P.; Golde, T.E.; Kayed, R.; Metherate, R.; Mattson, M.P.; Akbari, Y.; LaFerla, F.M. Triple-transgenic model of Alzheimer's Disease with plaques and tangles: Intracellular A $\beta$ and synaptic dysfunction. Neuron 2003, 39, 409-421. [CrossRef]

58. Tesseur, I.; Van Dorpe, J.; Spittaels, K.; Van den Haute, C.; Moechars, D.; Van Leuven, F. Expression of human apolipoprotein E4 in neurons causes hyperphosphorylation of protein tau in the brains of transgenic mice. Am. J. Pathol. 2000, 156, 951-964. [CrossRef]

59. Saito, T.; Matsuba, Y.; Mihira, N.; Takano, J.; Nilsson, P.; Itohara, S.; Iwata, N.; Saido, T.C. Single App knock-in mouse models of Alzheimer's disease. Nat. Neurosci. 2014, 17, 661-663. [CrossRef]

60. Genin, E.; Hannequin, D.; Wallon, D.; Sleegers, K.; Hiltunen, M.; Combarros, O.; Bullido, M.J.; Engelborghs, S.; De Deyn, P.; Berr, C.; et al. APOE and Alzheimer disease: A major gene with semi-dominant inheritance. Mol. Psychiatry 2011, 16, 903-907. [CrossRef]

61. Sims, R.; Van Der Lee, S.J.; Naj, A.C.; Bellenguez, C.; Badarinarayan, N.; Jakobsdottir, J.; Kunkle, B.W.; Boland, A.; Raybould, R.; Bis, J.C.; et al. Rare coding variants in PLCG2, ABI3, and TREM2 implicate microglial-mediated innate immunity in Alzheimer's disease. Nat. Genet. 2017, 49, 1373-1384. [CrossRef]

62. Waring, S.C.; Rosenberg, R.N. Genome-wide association studies in Alzheimer disease. Arch. Neurol. 2008, 65, 329-334. [CrossRef]

63. Lambert, J.C.; Ibrahim-Verbaas, C.A.; Harold, D.; Naj, A.C.; Sims, R.; Bellenguez, C.; Jun, G.; DeStefano, A.L.; Bis, J.C.; Beecham, G.W.; et al. Meta-analysis of 74,046 individuals identifies 11 new susceptibility loci for Alzheimer's disease. Nat. Genet. 2013, 45, 1452-1458. [CrossRef]

64. Saunders, A.; Macosko, E.Z.; Wysoker, A.; Goldman, M.; Krienen, F.M.; de Rivera, H.; Bien, E.; Baum, M.; Bortolin, L.; Wang, S.; et al. Molecular Diversity and Specializations among the Cells of the Adult Mouse Brain. Cell 2018, 174, 1015-1030. [CrossRef]

65. Zhang, Y.; Chen, K.; Sloan, S.A.; Bennett, M.L.; Scholze, A.R.; O’Keeffe, S.; Phatnani, H.P.; Guarnieri, P.; Caneda, C.; Ruderisch, N.; et al. An RNA-sequencing transcriptome and splicing database of glia, neurons, and vascular cells of the cerebral cortex. J. Neurosci. 2014, 34, 11929-11947. [CrossRef]

66. Cai, Y.; An, S.S.A.; Kim, S. Mutations in presenilin 2 and its implications in Alzheimer's disease and other dementia-associated disorders. Clin. Interv. Aging 2015, 10, 1163-1172. [CrossRef]

67. Kelleher, R.J.; Shen, J. Presenilin-1 mutations and Alzheimer's disease. Proc. Natl. Acad. Sci. USA 2017, 114, 629-631. [CrossRef]

68. Selkoe, D.J.; Hardy, J. The amyloid hypothesis of Alzheimer's disease at 25 years. EMBO Mol. Med. 2016, 8 , 595-608. [CrossRef]

69. Benzing, W.C.; Wujek, J.R.; Ward, E.K.; Shaffer, D.; Ashe, K.H.; Younkin, S.G.; Brunden, K.R. Evidence for glial-mediated inflammation in aged APP(SW) transgenic mice. Neurobiol. Aging 1999, 20, 581-589. [CrossRef]

70. Matsuoka, Y.; Picciano, M.; Maleste, B.; LaFrancois, J.; Zehr, C.; Daeschner, J.A.M.; Olschowka, J.A.; Fonseca, M.I.; O’Banion, M.K.; Tenner, A.J.; et al. Inflammatory responses to amyloidosis in a transgenic mouse model of Alzheimer's disease. Am. J. Pathol. 2001, 158, 1345-1354. [CrossRef]

71. Manaye, K.F.; Wang, P.C.; O’Neil, J.N.; Huang, S.Y.; Xu, T.; Lei, D.L.; Tizabi, Y.; Ottinger, M.A.; Ingram, D.K.; Mouton, P.R. Neuropathological quantification of dtg APP/PS1: Neuroimaging, stereology, and biochemistry. Age 2007, 29, 87-96. [CrossRef] 
72. Jorda, A.; Cauli, O.; Santonja, J.M.; Aldasoro, M.; Aldasoro, C.; Obrador, E.; Vila, J.M.; Mauricio, M.D.; Iradi, A.; Guerra-Ojeda, S.; et al. Changes in chemokines and chemokine receptors expression in a mouse model of alzheimer's disease. Int. J. Biol. Sci. 2019, 15, 453-463. [CrossRef]

73. Liu, L.; Liu, Y.; Li, N.; Huang, R.; Zheng, X.; Huang, L.; Hou, S.; Yuan, Q. Multiple inflammatory profiles of microglia and altered neuroimages in APP/PS1 transgenic AD mice. Brain Res. Bull. 2020, 156, 86-104. [CrossRef] [PubMed]

74. Jo, S.; Yarishkin, O.; Hwang, Y.J.; Chun, Y.E.; Park, M.; Woo, D.H.; Bae, J.Y.; Kim, T.; Lee, J.; Chun, H.; et al. GABA from reactive astrocytes impairs memory in mouse models of Alzheimer's disease. Nat. Med. 2014, 20, 886-896. [CrossRef]

75. Lian, H.; Litvinchuk, A.; Chiang, A.C.A.; Aithmitti, N.; Jankowsky, J.L.; Zheng, H. Astrocyte-microglia cross talk through complement activation modulates amyloid pathology in mouse models of alzheimer's disease. J. Neurosci. 2016, 36, 577-589. [CrossRef]

76. Sérrière, S.; Tauber, C.; Vercouillie, J.; Mothes, C.; Pruckner, C.; Guilloteau, D.; Kassiou, M.; Doméné, A.; Garreau, L.; Page, G.; et al. Amyloid load and translocator protein 18kDa in APPswePS1-dE9 mice: A longitudinal study. Neurobiol. Aging 2015, 36, 1639-1652. [CrossRef]

77. Ruan, L.; Kang, Z.; Pei, G.; Le, Y. Amyloid Deposition and Inflammation in APPswe/PS1dE9 Mouse Model of Alzheimer's Disease. Curr. Alzheimer Res. 2009, 6, 531-540. [CrossRef]

78. Kamphuis, W.; Orre, M.; Kooijman, L.; Dahmen, M.; Hol, E.M. Differential cell proliferation in the cortex of the APPswePS1dE9 Alzheimer's disease mouse model. Glia 2012, 60, 615-629. [CrossRef]

79. Janota, C.S.; Brites, D.; Lemere, C.A.; Brito, M.A. Glio-vascular changes during ageing in wild-type and Alzheimer's disease-like APP/PS1 mice. Brain Res. 2015, 1620, 153-168. [CrossRef]

80. Huang, H.; Nie, S.; Cao, M.; Marshall, C.; Gao, J.; Xiao, N.; Hu, G.; Xiao, M. Characterization of AD-like phenotype in aged APPSwe/PS1dE9 mice. Age 2016, 38, 303-322. [CrossRef]

81. Galea, E.; Morrison, W.; Hudry, E.; Arbel-Ornath, M.; Bacskai, B.J.; Gómez-Isla, T.; Stanley, H.E.; Hyman, B.T. Topological analyses in APP/PS1 mice reveal that astrocytes do not migrate to amyloid- $\beta$ plaques. Proc. Natl. Acad. Sci. USA 2015, 112, 15556-15561. [CrossRef]

82. Minkeviciene, R.; Ihalainen, J.; Malm, T.; Matilainen, O.; Keksa-Goldsteine, V.; Goldsteins, G.; Iivonen, H.; Leguit, N.; Glennon, J.; Koistinaho, J.; et al. Age-related decrease in stimulated glutamate release and vesicular glutamate transporters in APP/PS1 transgenic and wild-type mice. J. Neurochem. 2008, 105, 584-594. [CrossRef]

83. Jackson, H.M.; Soto, I.; Graham, L.C.; Carter, G.W.; Howell, G.R. Clustering of transcriptional profiles identifies changes to insulin signaling as an early event in a mouse model of Alzheimer's disease. BMC Genom. 2013, 14. [CrossRef] [PubMed]

84. Hong, S.; Beja-Glasser, V.F.; Nfonoyim, B.M.; Frouin, A.; Li, S.; Ramakrishnan, S.; Merry, K.M.; Shi, Q.; Rosenthal, A.; Barres, B.A.; et al. Complement and microglia mediate early synapse loss in Alzheimer mouse models. Science 2016, 352, 712-716. [CrossRef]

85. Shi, Q.; Chowdhury, S.; Ma, R.; Le, K.X.; Hong, S.; Caldarone, B.J.; Stevens, B.; Lemere, C.A. Complement C3 deficiency protects against neurodegeneration in aged plaque-rich APP/PS1 mice. Sci. Transl. Med. $2017,9$. [CrossRef]

86. Viña, J.; Lloret, A. Why women have more Alzheimer's disease than men: Gender and mitochondrial toxicity of amyloid- $\beta$ peptide. J. Alzheimers Dis. 2010, 20, 527-533. [CrossRef] [PubMed]

87. Turner, R.S. Alzheimer's disease in man and transgenic mice: Females at higher risk. Am. J. Pathol. 2001, 158, 797-801. [CrossRef]

88. Yang, J.T.; Wang, Z.J.; Cai, H.Y.; Yuan, L.; Hu, M.M.; Wu, M.N.; Qi, J.S. Sex Differences in Neuropathology and Cognitive Behavior in APP/PS1/tau Triple-Transgenic Mouse Model of Alzheimer's Disease. Neurosci. Bull. 2018, 34, 736-746. [CrossRef]

89. Carroll, J.C.; Rosario, E.R.; Kreimer, S.; Villamagna, A.; Gentzschein, E.; Stanczyk, F.Z.; Pike, C.J. Sex differences in $\beta$-amyloid accumulation in 3xTg-AD mice: Role of neonatal sex steroid hormone exposure. Brain Res. 2010, 1366, 233-245. [CrossRef]

90. Roy, U.; Stute, L.; Höfling, C.; Hartlage-Rübsamen, M.; Matysik, J.; Roßner, S.; Alia, A. Sex- and age-specific modulation of brain GABA levels in a mouse model of Alzheimer's disease. Neurobiol. Aging 2018, 62, 168-179. [CrossRef]

91. Kowalski, K.; Mulak, A. Brain-gut-microbiota axis in Alzheimer's disease. J. Neurogastroenterol. Motil. 2019, 25, 48-60. [CrossRef] 
92. Richetin, K.; Petsophonsakul, P.; Roybon, L.; Guiard, B.P.; Rampon, C. Differential alteration of hippocampal function and plasticity in females and males of the APPXPS1 mouse model of Alzheimer's disease. Neurobiol. Aging 2017, 57, 220-231. [CrossRef]

93. Kamphuis, W.; Mamber, C.; Moeton, M.; Kooijman, L.; Sluijs, J.A.; Jansen, A.H.P.; Verveer, M.; de Groot, L.R.; Smith, V.D.; Rangarajan, S.; et al. GFAP isoforms in adult mouse brain with a focus on neurogenic astrocytes and reactive astrogliosis in mouse models of Alzheimer disease. PLoS ONE 2012, 7, e42823. [CrossRef]

94. Ceyzériat, K.; Ben Haim, L.; Denizot, A.; Pommier, D.; Matos, M.; Guillemaud, O.; Palomares, M.A.; Abjean, L.; Petit, F.; Gipchtein, P.; et al. Modulation of astrocyte reactivity improves functional deficits in mouse models of Alzheimer's disease. Acta Neuropathol. Commun. 2018, 6, 104. [CrossRef]

95. Gomez-Arboledas, A.; Davila, J.C.; Sanchez-Mejias, E.; Navarro, V.; Nuñez-Diaz, C.; Sanchez-Varo, R.; Sanchez-Mico, M.V.; Trujillo-Estrada, L.; Fernandez-Valenzuela, J.J.; Vizuete, M.; et al. Phagocytic clearance of presynaptic dystrophies by reactive astrocytes in Alzheimer's disease. Glia 2018, 66, 637-653. [CrossRef]

96. Kimbrough, I.F.; Robel, S.; Roberson, E.D.; Sontheimer, H. Vascular amyloidosis impairs the gliovascular unit in a mouse model of Alzheimer's disease. Brain 2015, 138, 3716-3733. [CrossRef]

97. Beauquis, J.; Vinuesa, A.; Pomilio, C.; Pavia, P.; Galvan, V.; Saravia, F. Neuronal and Glial Alterations, Increased Anxiety, and Cognitive Impairment Before Hippocampal Amyloid Deposition in PDAPP Mice, Model of Alzheimer's Disease Juan. Hippocampus 2014, 24, 257-269. [CrossRef] [PubMed]

98. Yang, J.; Lunde, L.K.; Nuntagij, P.; Oguchi, T.; Camassa, L.M.A.; Nilsson, L.N.G.; Lannfelt, L.; Xu, Y.; Amiry-Moghaddam, M.; Ottersen, O.P.; et al. Loss of astrocyte polarization in the Tg-ArcSwe mouse model of Alzheimer's disease. J. Alzheimers Dis. 2011, 27, 711-722. [CrossRef] [PubMed]

99. Heiland, T.; Zeitschel, U.; Puchades, M.A.; Kuhn, P.H.; Lichtenthaler, S.F.; Bjaalie, J.G.; Hartlage-Rübsamen, M.; Roßner, S.; Höfling, C. Defined astrocytic expression of human amyloid precursor protein in Tg2576 mouse brain. Glia 2019, 67, 393-403. [CrossRef]

100. Waniek, A.; Hartlage-Rübsamen, M.; Höfling, C.; Kehlen, A.; Schilling, S.; Demuth, H.U.; Roßner, S. Identification of thyrotropin-releasing hormone as hippocampal glutaminyl cyclase substrate in neurons and reactive astrocytes. Biochim. Biophys. Acta Mol. Basis Dis. 2015, 1852, 146-155. [CrossRef]

101. Wilcock, D.M.; Vitek, M.P.; Colton, C.A. Vascular amyloid alters astrocytic water and potassium channels in mouse models and humans with Alzheimer's disease. Neuroscience 2009, 159, 1055-1069. [CrossRef] [PubMed]

102. Merlini, M.; Meyer, E.P.; Nitsch, A.U.R.M. Vascular $\beta$-amyloid and early astrocyte alterations impair cerebrovascular function and cerebral metabolism in transgenic arcA $\beta$ mice. Acta Neuropathol. 2011, $293-311$. [CrossRef]

103. Ugolini, F.; Lana, D.; Nardiello, P.; Nosi, D.; Pantano, D.; Casamenti, F.; Giovannini, M.G. Different Patterns of Neurodegeneration and Glia Activation in CA1 and CA3 Hippocampal Regions of TgCRND8 Mice. Front. Aging Neurosci. 2018, 10, 1-23. [CrossRef]

104. Freeman, M.R. Specification and morphogenesis of astrocytes. Science 2010, 330, 774-778. [CrossRef]

105. Lanjakornsiripan, D.; Pior, B.J.; Kawaguchi, D.; Furutachi, S.; Tahara, T.; Katsuyama, Y.; Suzuki, Y.; Fukazawa, Y.; Gotoh, Y. Layer-specific morphological and molecular differences in neocortical astrocytes and their dependence on neuronal layers. Nat. Commun. 2018, 9. [CrossRef]

106. Rockenstein, E.; Mallory, M.; Mante, M.; Sisk, A.; Masliaha, E. Early formation of mature amyloid- $\beta$ protein deposits in a mutant APP transgenic model depends on levels of Aß1-42. J. Neurosci. Res. 2001, 66, 573-582. [CrossRef]

107. Hsiao, K.; Chapman, P.; Nilsen, S.; Eckman, C.; Harigaya, Y.; Younkin, S.; Yang, F.; Cole, G. Correlative Memory Deficits, A $\beta$ Elevation, and Amyloid Plaques in Transgenic Mice. Science 1996, 274, 99-102. [CrossRef]

108. Rönnbäck, A.; Sagelius, H.; Bergstedt, K.D.; Näslund, J.; Westermark, G.T.; Winblad, B.; Graff, C. Amyloid neuropathology in the single Arctic APP transgenic model affects interconnected brain regions. Neurobiol. Aging 2012, 33, 11-19. [CrossRef]

109. Lord, A.; Kalimo, H.; Eckman, C.; Zhang, X.Q.; Lannfelt, L.; Nilsson, L.N.G. The Arctic Alzheimer mutation facilitates early intraneuronal A $\beta$ aggregation and senile plaque formation in transgenic mice. Neurobiol. Aging 2006, 27, 67-77. [CrossRef] [PubMed]

110. Davis, J.; Xu, F.; Deane, R.; Romanov, G.; Previti, M.L.; Zeigler, K.; Zlokovic, B.V.; Van Nostrand, W.E. Early-onset and Robust Cerebral Microvascular Accumulation of Amyloid $\beta$-Protein in Transgenic Mice Expressing Low Levels of a Vasculotropic Dutch/Iowa Mutant Form of Amyloid $\beta$-Protein Precursor. J. Biol. Chem. 2004, 279, 20296-20306. [CrossRef] 
111. Oakley, H.; Cole, S.L.; Logan, S.; Maus, E.; Shao, P.; Craft, J.; Guillozet-Bongaarts, A.; Ohno, M.; Disterhoft, J.; Van Eldik, L.; et al. Intraneuronal $\beta$-amyloid aggregates, neurodegeneration, and neuron loss in transgenic mice with five familial Alzheimer's disease mutations: Potential factors in amyloid plaque formation. J. Neurosci. 2006, 26, 10129-10140. [CrossRef]

112. Radde, R.; Bolmont, T.; Kaeser, S.A.; Coomaraswamy, J.; Lindau, D.; Stoltze, L.; Calhoun, M.E.; Jäggi, F.; Wolburg, H.; Gengler, S.; et al. A $\beta 42$-driven cerebral amyloidosis in transgenic mice reveals early and robust pathology. EMBO Rep. 2006, 7, 940-946. [CrossRef]

113. Jankowsky, J.L.; Fadale, D.J.; Anderson, J.; Xu, G.M.; Gonzales, V.; Jenkins, N.A.; Copeland, N.G.; Lee, M.K.; Younkin, L.H.; Wagner, S.L.; et al. Mutant presenilins specifically elevate the levels of the 42 residue $\beta$-amyloid peptide in vivo: Evidence for augmentation of a 42-specific $\gamma$ secretase. Hum. Mol. Genet. 2004, 13, 159-170. [CrossRef]

114. Jankowsky, J.L.; Slunt, H.H.; Ratovitski, T.; Jenkins, N.A.; Copeland, N.G.; Borchelt, D.R. Co-expression of multiple transgenes in mouse CNS: A comparison of strategies. Biomol. Eng. 2001, 17, 157-165. [CrossRef]

115. Blanchard, V.; Moussaoui, S.; Czech, C.; Touchet, N.; Bonici, B.; Planche, M.; Canton, T.; Jedidi, I.; Gohin, M.; Wirths, O.; et al. Time sequence of maturation of dystrophic neurites associated with A $\beta$ deposits in APP/PS1 transgenic mice. Exp. Neurol. 2003, 184, 247-263. [CrossRef]

116. Richards, J.G.; Higgins, G.A.; Ouagazzal, A.M.; Ozmen, L.; Kew, J.N.C.; Bohrmann, B.; Malherbe, P.; Brockhaus, M.; Loetscher, H.; Czech, C.; et al. PS2APP transgenic mice, coexpressing hPS2mut and hAPPswe, show age-related cognitive deficits associated with discrete brain amyloid deposition and inflammation. J. Neurosci. 2003, 23, 8989-9003. [CrossRef] [PubMed]

117. Yoshiyama, Y.; Higuchi, M.; Zhang, B.; Huang, S.M.; Iwata, N.; Saido, T.C.C.; Maeda, J.; Suhara, T.; Trojanowski, J.Q.; Lee, V.M.Y. Synapse Loss and Microglial Activation Precede Tangles in a P301S Tauopathy Mouse Model. Neuron 2007, 53, 337-351. [CrossRef]

118. Tatebayashi, Y.; Miyasaka, T.; Chui, D.H.; Akagi, T.; Mishima, K.I.; Iwasaki, K.; Fujiwara, M.; Tanemura, K.; Murayama, M.; Ishiguro, K.; et al. Tau filament formation and associative memory deficit in aged mice expressing mutant (R406W) human tau. Proc. Natl. Acad. Sci. USA 2002, 99, 13896-13901. [CrossRef]

119. Ramsden, M.; Kotilinek, L.; Forster, C.; Paulson, J.; Mcgowan, E.; Santacruz, K.; Guimaraes, A.; Yue, M.; Lewis, J.; Carlson, G.; et al. Age-Dependent Neurofibrillary Tangle Formation, Neuron Loss, and Memory Impairment in a Mouse Model of Human Tauopathy (P301L). Neurobiol. Dis. 2005, 25, 10637-10647. [CrossRef]

120. SantaCruz, K.; Lewis, J.; Spires, T.; Paulson, J.; Kotilinek, L.; Ingelsson, M.; Guimaraes, A.; DeTure, M.; Ramsden, M.; McGowan, E.; et al. Tau Suppression in a Neurodegenerative Mouse Model Improves Memory Function. Science 2005, 309. [CrossRef]

121. Liu, L.; Drouet, V.; Wu, J.W.; Witter, M.P.; Small, S.A.; Clelland, C.; Duff, K. Trans-synaptic spread of tau pathology in vivo. PLoS ONE 2012, 7, e31302. [CrossRef]

122. De Calignon, A.; Polydoro, M.; Suárez-Calvet, M.; William, C.; Adamowicz, D.H.; Kopeikina, K.J.; Pitstick, R.; Sahara, N.; Ashe, K.H.; Carlson, G.A.; et al. Propagation of Tau Pathology in a Model of Early Alzheimer's Disease. Neuron 2012, 73, 685-697. [CrossRef]

123. Serrano-Pozo, A.; Gómez-Isla, T.; Growdon, J.H.; Frosch, M.P.; Hyman, B.T. A phenotypic change but not proliferation underlies glial responses in Alzheimer disease. Am. J. Pathol. 2013, 182, 2332-2344. [CrossRef]

124. Perez-Nievas, B.G.; Serrano-Pozo, A. Deciphering the astrocyte reaction in Alzheimer's disease. Front. Aging Neurosci. 2018, 10, 1-23. [CrossRef]

125. Wang, D.; Zhang, X.; Wang, M.; Zhou, D.; Pan, H.; Shu, Q.; Sun, B. Early Activation of Astrocytes does not Affect Amyloid Plaque Load in an Animal Model of Alzheimer's Disease. Neurosci. Bull. 2018, 34, 912-920. [CrossRef] [PubMed]

126. Chai, H.; Diaz-Castro, B.; Shigetomi, E.; Monte, E.; Octeau, J.C.; Yu, X.; Cohn, W.; Rajendran, P.S.; Vondriska, T.M.; Whitelegge, J.P.; et al. Neural Circuit-Specialized Astrocytes: Transcriptomic, Proteomic, Morphological, and Functional Evidence. Neuron 2017, 95, 531-549. [CrossRef]

127. Bayraktar, O.A.; Bartels, T.; Holmqvist, S.; Kleshchevnikov, V.; Martirosyan, A.; Polioudakis, D.; Ben Haim, L.; Young, A.M.H.; Batiuk, M.Y.; Prakash, K.; et al. Astrocyte layers in the mammalian cerebral cortex revealed by a single-cell in situ transcriptomic map. Nat. Neurosci. 2020, 23, 500-509. [CrossRef]

128. Xiao, Q.; Yan, P.; Ma, X.; Liu, H.; Perez, R.; Zhu, A.; Gonzales, E.; Burchett, J.M.; Schuler, D.R.; Cirrito, J.R.; et al. Enhancing astrocytic lysosome biogenesis facilitates $\mathrm{A} \beta$ clearance and attenuates amyloid plaque pathogenesis. J. Neurosci. 2014, 34, 9607-9620. [CrossRef] 
129. Jones, R.S.; Minogue, A.M.; Connor, T.J.; Lynch, M.A. Amyloid- $\beta$-induced astrocytic phagocytosis is mediated by CD36, CD47 and RAGE. J. Neuroimmune Pharmacol. 2013, 8, 301-311. [CrossRef]

130. Wyss-Coray, T.; Loike, J.D.; Brionne, T.C.; Lu, E.; Anankov, R.; Yan, F.; Silverstein, S.C.; Husemann, J. Adult mouse astrocytes degrade amyloid- $\beta$ in vitro and in situ. Nat. Med. 2003, 9, 453-457. [CrossRef]

131. Lee, Y.; Messing, A.; Su, M.; Brenner, M. GFAP promoter elements required for region-specific and astrocyte-specific expression. Glia 2008, 56, 481-493. [CrossRef]

132. Mader, S.; Brimberg, L. Aquaporin- 4 Water Channel in the Brain and Its Implication for Health and Disease. Cells 2019, 8, 90. [CrossRef]

133. Chandra, A.; Farrell, C.; Wilson, H.; Dervenoulas, G.; De Natale, E.R.; Politis, M. Aquaporin-4 polymorphisms predict amyloid burden and clinical outcome in the Alzheimer's disease spectrum. Neurobiol. Aging 2020. [CrossRef]

134. Xu, Z.; Xiao, N.; Chen, Y.; Huang, H.; Marshall, C.; Gao, J.; Cai, Z.; Wu, T.; Hu, G.; Xiao, M. Deletion of aquaporin-4 in APP/PS1 mice exacerbates brain A $\beta$ accumulation and memory deficits. Mol. Neurodegener. 2015, 10, 1-16. [CrossRef]

135. Sloan, S.A.; Darmanis, S.; Huber, N.; Khan, T.; Birey, F.; Caneda, C.; Reimer, R.; Quake, S.R.; Barres, B.A.; Sergiu, P. Human Astrocyte Maturation Captured in 3D Cerebral Cortical Spheroids Derived from Pluripotent Stem Cells. Neuron 2017, 95, 779-790. [CrossRef]

136. Marton, R.M.; Pașca, S.P. Organoid and Assembloid Technologies for Investigating Cellular Crosstalk in Human Brain Development and Disease. Trends Cell Biol. 2020, 30, 133-143. [CrossRef]

137. Barbar, L.; Jain, T.; Zimmer, M.; Kruglikov, I.; Sadick, J.S.; Wang, M.; Kalpana, K.; Rose, I.V.L.; Burstein, S.R.; Rusielewicz, T.; et al. CD49f Is a Novel Marker of Functional and Reactive Human iPSC-Derived Astrocytes. Neuron 2020, 107, 436-453. [CrossRef]

138. Johnson, G.V.W.; Stoothoff, W.H. Tau phosphorylation in neuronal cell function and dysfunction. J. Cell Sci. 2004, 117, 5721-5729. [CrossRef]

139. Noble, W.; Hanger, D.P.; Miller, C.C.J.; Lovestone, S. The importance of tau phosphorylation for neurodegenerative diseases. Front. Neurol. 2013, 4, 1-11. [CrossRef] [PubMed]

140. Hampton, D.W.; Webber, D.J.; Bilican, B.; Goedert, M.; Spillantini, M.G.; Chandran, S. Cell-mediated neuroprotection in a mouse model of human tauopathy. J. Neurosci. 2010, 30, 9973-9983. [CrossRef]

141. Crescenzi, R.; DeBrosse, C.; Nanga, R.P.R.; Byrne, M.D.; Krishnamoorthy, G.; D'aquilla, K.; Al, E. Longitudinal imaging reveals sub-hippocampal dynamics in glutamate levels associated with histopathologic events in a mouse model of tauopathy and healthy mice. Hippocampus 2017, 27, 285-302. [CrossRef] [PubMed]

142. Fu, H.; Hussaini, S.A.; Wegmann, S.; Profaci, C.; Daniels, J.D.; Herman, M.; Emrani, S.; Figueroa, H.Y.; Hyman, B.T.; Davies, P.; et al. 3D Visualization of the temporal and spatial spread of tau pathology reveals extensive sites of tau accumulation associated with neuronal loss and recognition memory deficit in aged tau transgenic mice. PLoS ONE 2016, 11, e159463. [CrossRef]

143. Nilson, A.N.; English, K.C.; Gerson, J.E.; Whittle, T.B. Tau Oligomers Associate with Inflammation in the Brain and Retina of Tauopathy Mice and in Neurodegenerative Diseases. J. Alzheimers Dis. 2017, 55, 1083-1099. [CrossRef]

144. Helboe, L.; Egebjerg, J.; Barkholt, P.; Volbracht, C. Early depletion of CA1 neurons and late neurodegeneration in a mouse tauopathy model. Brain Res. 2017, 1665, 22-35. [CrossRef] [PubMed]

145. Spires, T.L.; Orne, J.D.; SantaCruz, K.; Pitstick, R.; Carlson, G.A.; Ashe, K.H.; Hyman, B.T. Region-specific dissociation of neuronal loss and neurofibrillary pathology in a mouse model of tauopathy. Am. J. Pathol. 2006, 168, 1598-1607. [CrossRef]

146. Ricklin, D.; Reis, Edimara, S.; Mastellos, D.S.; Gros, P.; Lambris, J.D. Complement component C3-The "Swiss Army Knife" of innate immunity and host defense. Immunol. Rev. 2016, 274, 33-58. [CrossRef]

147. Litvinchuk, A.; Wan, Y.W.; Swartzlander, D.B.; Chen, F.; Cole, A.; Propson, N.E.; Wang, Q.; Zhang, B.; Liu, Z.; Zheng, H. Complement C3aR Inactivation Attenuates Tau Pathology and Reverses an Immune Network Deregulated in Tauopathy Models and Alzheimer's Disease. Neuron 2018, 100, 1337-1353. [CrossRef]

148. Shiratori-Hayashi, M.; Koga, K.; Tozaki-Saitoh, H.; Kohro, Y.; Toyonaga, H.; Yamaguchi, C.; Hasegawa, A.; Nakahara, T.; Hachisuka, J.; Akira, S.; et al. STAT3-dependent reactive astrogliosis in the spinal dorsal horn underlies chronic itch. Nat. Med. 2015, 21, 927-931. [CrossRef]

149. Clarke, L.E.; Liddelow, S.A.; Chakraborty, C.; Münch, A.E.; Heiman, M. Normal aging induces A1-like astrocyte reactivity. Proc. Natl. Acad. Sci. USA 2018, 115, E1896-E1905. [CrossRef] 
150. Brunello, C.A.; Merezhko, M.; Uronen, R.L.; Huttunen, H.J. Mechanisms of secretion and spreading of pathological tau protein. Cell. Mol. Life Sci. 2019, 77, 1721-1744. [CrossRef] [PubMed]

151. Gibbons, G.S.; Lee, V.M.Y.; Trojanowski, J.Q. Mechanisms of Cell-to-Cell Transmission of Pathological Tau: A Review. JAMA Neurol. 2019, 76, 101-108. [CrossRef]

152. Franzmeier, N.; Rubinski, A.; Neitzel, J.; Kim, Y.; Damm, A.; Na, D.L.; Kim, H.J.; Lyoo, C.H.; Cho, H.; Finsterwalder, S.; et al. Functional connectivity associated with tau levels in ageing, Alzheimer's, and small vessel disease. Brain 2019, 142, 1093-1107. [CrossRef]

153. Wu, J.W.; Hussaini, S.A.; Bastille, I.M.; Rodriguez, G.A.; Mrejeru, A.; Rilett, K.; Sanders, D.W.; Cook, C.; $\mathrm{Fu}, \mathrm{H} . ;$ Boonen, R.A.C.M.; et al. Neuronal activity enhances tau propagation and tau pathology in vivo. Nat. Neurosci. 2016, 19, 1085-1092. [CrossRef]

154. Perea, G.; Navarrete, M.; Araque, A. Tripartite synapses: Astrocytes process and control synaptic information. Trends Neurosci. 2009, 32, 421-431. [CrossRef]

155. Perea, J.R.; López, E.; Diéz-Ballesteros, J.C.; Ávila, J.; Hernández, F.; Bolós, M. Extracellular monomeric tau is internalized by astrocytes. Front. Neurosci. 2019, 13,1-7. [CrossRef]

156. Otero-Garcia, M.; Xue, Y.-Q.; Shakouri, T.; Deng, Y.; Morabito, S.; Allison, T.; Lowry, W.E.; Kawaguchi, R.; Swarup, V.; Cobos, I. Single-soma transcriptomics of tangle-bearing neurons in Alzheimer's disease reveals the signatures of tau-associated synaptic dysfunction. BioRxiv 2020. [CrossRef]

157. Ikeda, M.; Shoji, M.; Kawarai, T.; Kawarabayashi, T.; Matsubara, E.; Murakami, T.; Sasaki, A.; Tomidokoro, Y.; Ikarashi, Y.; Kuribara, H.; et al. Accumulation of filamentous tau in the cerebral cortex of human tau R406W transgenic mice. Am. J. Pathol. 2005, 166, 521-531. [CrossRef]

158. Narasimhan, S.; Guo, J.L.; Changolkar, L.; Stieber, A.; McBride, J.D.; Silva, L.V.; He, Z.; Zhang, B.; Gathagan, R.J.; Trojanowski, J.Q.; et al. Pathological tau strains from human brains recapitulate the diversity of tauopathies in nontransgenic mouse brain. J. Neurosci. 2017, 37, 11406-11423. [CrossRef]

159. Lin, W.L.; Lewis, J.; Yen, S.H.; Hutton, M.; Dickson, D.W. Filamentous tau in oligodendrocytes and astrocytes of transgenic mice expressing the human tau isoform with the P301L mutation. Am. J. Pathol. 2003, 162, $213-218$. [CrossRef]

160. Bronzuoli, M.R.; Facchinetti, R.; Valenza, M.; Cassano, T.; Steardo, L.; Scuderi, C. Astrocyte function is affected by aging and not Alzheimer's disease: A preliminary investigation in hippocampi of 3xTg-AD mice. Front. Pharmacol. 2019, 10, 1-9. [CrossRef] [PubMed]

161. Griffith, C.M.; Xie, M.X.; Qiu, W.Y.; Sharp, A.A.; Ma, C.; Pan, A.; Yan, X.X.; Patrylo, P.R. Aberrant expression of the pore-forming KATP channel subunit Kir6.2 in hippocampal reactive astrocytes in the 3xTg-AD mouse model and human Alzheimer's disease. Neuroscience 2016, 336, 81-101. [CrossRef]

162. Wyssenbach, A.; Quintela, T.; Llavero, F.; Zugaza, J.L.; Matute, C.; Alberdi, E. Amyloid $\beta$-induced astrogliosis is mediated by $\beta 1$-integrin via NADPH oxidase 2 in Alzheimer's disease. Aging Cell 2016, 15, 1140-1152. [CrossRef]

163. Grimaldi, A.; Brighi, C.; Peruzzi, G.; Ragozzino, D.; Bonanni, V.; Limatola, C.; Ruocco, G.; Di Angelantonio, S. Inflammation, neurodegeneration and protein aggregation in the retina as ocular biomarkers for Alzheimer's disease in the 3xTg-AD mouse model. Cell Death Dis. 2018, 9. [CrossRef]

164. Ontiveros-Torres, M.A.; Labra-Barrios, M.L.; Diaz-Cintra, S.; Aguilar-Vazquez, R.A.; Al, E. Fibrillar Amyloid- $\beta$ Accumulation Triggers an Inflammatory Mechanism Leading to Hyperphosphorylation of the Carboxyl-Terminal End of Tau Polypeptide in the Hippocampal Formation of the $3 \times$ Tg-AD Transgenic Mouse. J. Alzheimers Dis. 2016, 52, 243-269. [CrossRef]

165. Guedes, J.R.; Custódia, C.M.; Silva, R.J.; de Almeida, L.P.; de Lima, M.C.P.; Cardoso, A.L. Early miR-155 upregulation contributes to neuroinflammation in Alzheimer's disease triple transgenic mouse model. Hum. Mol. Genet. 2014, 23, 6286-6301. [CrossRef] [PubMed]

166. Mckeon-O'Malley, C.; Tanzi, R. Etiology, Genetics, and Pathogenesis of Alzheimer's Disease. Funct. Neurobiol. Aging 2001, 333-348. [CrossRef]

167. Verghese, P.B.; Castellano, J.M.; Holtzman, D.M. Apolipoprotein E in Alzheimer's disease and other neurological disorders. Lancet Neurol. 2011, 10, 241-252. [CrossRef]

168. Zhu, Y.; Nwabuisi-Heath, E.; Dumanis, S.B.; Tai, L.M.; Yu, C.; Rebeck, G.W.; Ladu, M.J. APOE genotype alters glial activation and loss of synaptic markers in mice. Glia 2012, 60, 559-569. [CrossRef] 
169. Hussain, G.; Wang, J.; Rasul, A.; Anwar, H.; Imran, A.; Qasim, M.; Zafar, S.; Kamran, S.K.S.; Razzaq, A.; Aziz, N.; et al. Role of cholesterol and sphingolipids in brain development and neurological diseases. Lipids Health Dis. 2019, 18, 1-12. [CrossRef]

170. Zheng, J.; Sun, J.; Ji, C.; Shen, L.; Chen, Z.; Xie, P.; Sun, Y.Z.; Yu, R. Selective deletion of apolipoprotein E in astrocytes ameliorates the spatial learning and memory deficits in Alzheimer's disease (APP/PS1) mice by inhibiting TGF- $\beta /$ Smad2/STAT3 signaling. Neurobiol. Aging 2017, 54, 112-132. [CrossRef]

171. Bales, K.R.; Verina, T.; Cummins, D.J.; Du, Y.; Dodel, R.C.; Saura, J.; Fishman, C.E.; Delong, C.A.; Piccardo, P.; Petegnief, V.; et al. Apolipoprotein E is essential for amyloid deposition in the APP(V717F) transgenic mouse model of Alzheimer's disease. Proc. Natl. Acad. Sci. USA 1999, 96, 15233-15238. [CrossRef] [PubMed]

172. Rodriguez, G.A.; Tai, L.M.; LaDu, M.J.; Rebeck, G.W. Human APOE4 increases microglia reactivity at A $\beta$ plaques in a mouse model of $\mathrm{A} \beta$ deposition. J. Neuroinflamm. 2014, 11. [CrossRef]

173. Dorey, E.; Bamji-Mirza, M.; Najem, D.; Li, Y.; Liu, H.; Callaghan, D.; Walker, D.; Lue, L.F.; Stanimirovic, D.; Zhang, W. Apolipoprotein E Isoforms Differentially Regulate Alzheimer's Disease and Amyloid- $\beta$-Induced Inflammatory Response in vivo and in vitro. J. Alzheimers Dis. 2017, 57, 1265-1279. [CrossRef]

174. Zhang, R.; Wu, Y.; Xie, F.; Zhong, Y.; Wang, Y.; Xu, M.; Feng, J.; Charish, J.; Monnier, P.P.; Qin, X. RGMa mediates reactive astrogliosis and glial scar formation through TGF $\beta 1 / \mathrm{Smad} 2 / 3$ signaling after stroke. Cell Death Differ. 2018, 25, 1503-1516. [CrossRef]

175. Rolyan, H.; Feike, A.C.; Upadhaya, A.R.; Waha, A.; Van Dooren, T.; Haass, C.; Birkenmeier, G.; Pietrzik, C.U.; Van Leuven, F.; Thal, D.R. Amyloid- $\beta$ protein modulates the perivascular clearance of neuronal apolipoprotein e in mouse models of Alzheimer's disease. J. Neural Transm. 2011, 118, 699-712. [CrossRef]

176. Shi, Y.; Yamada, K.; Liddelow, S.A.; Smith, S.T.; Zhao, L.; Luo, W.; Tsai, R.M.; Spina, S.; Grinberg, L.T.; Rojas, J.C.; et al. ApoE4 markedly exacerbates tau-mediated neurodegeneration in a mouse model of tauopathy. Nature 2017, 549, 523-527. [CrossRef]

177. Ulland, T.K.; Colonna, M. TREM2-A key player in microglial biology and Alzheimer disease. Nat. Rev. Neurol. 2018, 14, 667-675. [CrossRef]

178. Turnbull, I.R.; Gilfillan, S.; Cella, M.; Aoshi, T.; Miller, M.; Piccio, L.; Hernandez, M.; Colonna, M. Cutting Edge: TREM-2 Attenuates Macrophage Activation. J. Immunol. 2006, 177, 3520-3524. [CrossRef] [PubMed]

179. Leyns, C.E.G.; Ulrich, J.D.; Finn, M.B.; Stewart, F.R.; Koscal, L.J.; Serrano, J.R.; Robinson, G.O.; Anderson, E.; Colonna, M.; Holtzman, D.M. TREM2 deficiency attenuates neuroinflammation and protects against neurodegeneration in a mouse model of tauopathy. Proc. Natl. Acad. Sci. USA 2017, 114, 11524-11529. [CrossRef] [PubMed]

180. Zhang, Y.; Sloan, S.A.; Clarke, L.E.; Caneda, C.; Plaza, C.A.; Blumenthal, P.D.; Vogel, H.; Steinberg, G.K.; Edwards, M.S.B.; Li, G.; et al. Purification and Characterization of Progenitor and Mature Human Astrocytes Reveals Transcriptional and Functional Differences with Mouse. Neuron 2016, 89, 37-53. [CrossRef]

181. Oberheim, N.A.; Takano, T.; Han, X.; He, W.; Lin, J.H.C.; Wang, F.; Xu, Q.; Wyatt, J.D.; Pilcher, W.; Ojemann, J.G.; et al. Uniquely hominid features of adult human astrocytes. J. Neurosci. 2009, 29, 3276-3287. [CrossRef]

182. Windrem, M.S.; Schanz, S.J.; Morrow, C.; Munir, J.; Chandler-Militello, D.; Wang, S.; Goldman, S.A. A competitive advantage by neonatally engrafted human glial progenitors yields mice whose brains are chimeric for human glia. J. Neurosci. 2014, 34, 16153-16161. [CrossRef]

183. Hsu, E.T.; Gangolli, M.; Su, S.; Holleran, L.; Stein, T.D.; Alvarez, V.E.; McKee, A.C.; Schmidt, R.E.; Brody, D.L. Astrocytic degeneration in chronic traumatic encephalopathy. Acta Neuropathol. 2018, 136, 955-972. [CrossRef]

184. Krutzik, S.R.; Tan, B.; Li, H.; Ochoa, M.T.; Liu, P.T.; Sharfstein, S.E.; Graeber, T.G.; Sieling, P.A.; Liu, Y.J.; Rea, T.H.; et al. TLR activation triggers the rapid differentiation of monocytes into macrophages and dendritic cells. Nat. Med. 2005, 11, 653-660. [CrossRef] [PubMed]

185. Underhill, D.M.; Ozinsky, A.; Hajjar, A.M.; Stevens, A.; Wilson, C.B.; Bassetti, M.; Aderem, A. The Toll-like receptor 2 is recruited to macrophage phagosomes and discriminates between pathogens. Nature 1999, 401, 811-815. [CrossRef]

186. Frederiksen, H.R.; Haukedal, H.; Freude, K.; Muthuraju, S. Cell type specific expression of toll-like receptors in human brains and implications in Alzheimer's disease. Biomed. Res. Int. 2019, 2019. [CrossRef]

187. Bauer, S.; Kirschning, C.J.; Häcker, H.; Redecke, V.; Hausmann, S.; Akira, S.; Wagner, H.; Lipford, G.B. Human TLR9 confers responsiveness to bacterial DNA via species-specific CpG motif recognition. Proc. Natl. Acad. Sci. USA 2001, 98, 9237-9242. [CrossRef] [PubMed] 
188. Jones, V.C.; Atkinson-Dell, R.; Verkhratsky, A.; Mohamet, L. Aberrant iPSC-derived human astrocytes in Alzheimer's disease. Cell Death Dis. 2017, 8, 1-11. [CrossRef]

189. Kondo, T.; Asai, M.; Tsukita, K.; Kutoku, Y.; Ohsawa, Y.; Sunada, Y.; Imamura, K.; Egawa, N.; Yahata, N.; Okita, K.; et al. Modeling Alzheimer's disease with iPSCs reveals stress phenotypes associated with intracellular A $\beta$ and differential drug responsiveness. Cell Stem Cell 2013, 12, 487-496. [CrossRef]

190. Lin, Y.T.; Seo, J.; Gao, F.; Feldman, H.M.; Wen, H.L.; Penney, J.; Cam, H.P.; Gjoneska, E.; Raja, W.K.; Cheng, J.; et al. APOE4 Causes Widespread Molecular and Cellular Alterations Associated with Alzheimer's Disease Phenotypes in Human iPSC-Derived Brain Cell Types. Neuron 2018, 98, 1141-1154. [CrossRef]

191. Niccoli, T.; Partridge, L. Ageing as a risk factor for disease. Curr. Biol. 2012, 22, R741-R752. [CrossRef]

192. Soreq, L.; Rose, J.; Soreq, E.; Hardy, J.; Trabzuni, D.; Cookson, M.R.; Smith, C.; Ryten, M.; Patani, R.; Ule, J. Major Shifts in Glial Regional Identity Are a Transcriptional Hallmark of Human Brain Aging. Cell Rep. 2017, 18, 557-570. [CrossRef]

193. Boisvert, M.M.; Erikson, G.A.; Shokhirev, M.N.; Allen, N.J. The Aging Astrocyte Transcriptome from Multiple Regions of the Mouse Brain. Cell Rep. 2018, 22, 269-285. [CrossRef] [PubMed]

194. Shen, L.; Liu, L.; Ji, H.F. Alzheimer's disease histological and behavioral manifestations in transgenic mice correlate with specific gut microbiome state. J. Alzheimers Dis. 2017, 56, 385-390. [CrossRef]

195. Sochocka, M.; Donskow-Łysoniewska, K.; Diniz, B.S.; Kurpas, D.; Brzozowska, E.; Leszek, J. The Gut Microbiome Alterations and Inflammation-Driven Pathogenesis of Alzheimer's Disease-A Critical Review. Mol. Neurobiol. 2019, 56, 1841-1851. [CrossRef]

196. Harach, T.; Marungruang, N.; Duthilleul, N.; Cheatham, V.; Mc Coy, K.D.; Frisoni, G.; Neher, J.J.; Fåk, F.; Jucker, M.; Lasser, T.; et al. Reduction of Abeta amyloid pathology in APPPS1 transgenic mice in the absence of gut microbiota. Sci. Rep. 2017, 7. [CrossRef]

197. Rothhammer, V.; Mascanfroni, I.D.; Bunse, L.; Takenaka, M.C.; Kenison, J.E.; Mayo, L.; Chao, C.C.; Patel, B.; Yan, R.; Blain, M.; et al. Type I interferons and microbial metabolites of tryptophan modulate astrocyte activity and central nervous system inflammation via the aryl hydrocarbon receptor. Nat. Med. 2016, 22, 586-597. [CrossRef] [PubMed]

198. Marizzoni, M.; Cattaneo, A.; Mirabello, P.; Festari, C.; Lopizzo, N.; Nicolosi, V.; Mombelli, E.; Mazzelli, M.; Luongo, D.; Naviglio, D.; et al. Short-chain fatty acids and lipopolysaccharide as mediators between gut dysbiosis and amyloid pathology in Alzheimer's Disease. J. Alzheimers. Dis. 2020. [CrossRef]

199. Moir, R.D.; Lathe, R.; Tanzi, R.E. The antimicrobial protection hypothesis of Alzheimer's disease. Alzheimers Dement. 2018, 14, 1602-1614. [CrossRef]

200. Casellas, J. Inbred mouse strains and genetic stability: A review. Animal 2011, 5, 1-7. [CrossRef]

201. Park, R.; Kook, S.Y.; Park, J.C.; Mook-Jung, I. A $\beta 1-42$ reduces P-glycoprotein in the blood-brain barrier through RAGE-NF-кB signaling. Cell Death Dis. 2014, 5, 1-11. [CrossRef] [PubMed]

202. Letronne, F.; Laumet, G.; Ayral, A.M.; Chapuis, J.; Demiautte, F.; Laga, M.; Vandenberghe, M.E.; Malmanche, N.; Leroux, F.; Eysert, F.; et al. ADAM30 Downregulates APP-Linked Defects Through Cathepsin D Activation in Alzheimer's Disease. EBioMedicine 2016, 9, 278-292. [CrossRef]

203. Urbanelli, L.; Emiliani, C.; Massini, C.; Persichetti, E.; Orlacchio, A.; Pelicci, G.; Sorbi, S.; Hasilik, A.; Bernardi, G.; Orlacchio, A. Cathepsin D expression is decreased in Alzheimer's disease fibroblasts. Neurobiol. Aging 2008, 29, 12-22. [CrossRef] [PubMed]

204. Chai, Y.L.; Chong, J.R.; Weng, J.; Howlett, D.; Halsey, A.; Lee, J.H.; Attems, J.; Aarsland, D.; Francis, P.T.; Chen, C.P.; et al. Lysosomal cathepsin D is upregulated in Alzheimer's disease neocortex and may be a marker for neurofibrillary degeneration. Brain Pathol. 2019, 29, 63-74. [CrossRef]

205. Yin, C.; Ackermann, S.; Ma, Z.; Mohanta, S.K.; Zhang, C.; Li, Y.; Nietzsche, S.; Westermann, M.; Peng, L.; $\mathrm{Hu}$, D.; et al. ApoE attenuates unresolvable inflammation by complex formation with activated C1q. Nat. Med. 2019, 25, 496-506. [CrossRef]

206. Das, S.; Li, Z.; Noori, A.; Hyman, B.T.; Serrano-Pozo, A. Meta-analysis of mouse transcriptomic studies supports a context-dependent astrocyte reaction in acute CNS injury versus neurodegeneration. J. Neuroinflamm. 2020, 17, 227. [CrossRef]

207. Wang, M.; Roussos, P.; McKenzie, A.; Zhou, X.; Kajiwara, Y.; Brennand, K.J.; De Luca, G.C.; Crary, J.F.; Casaccia, P.; Buxbaum, J.D.; et al. Integrative network analysis of nineteen brain regions identifies molecular signatures and networks underlying selective regional vulnerability to Alzheimer's disease. Genome Med. 2016, 8, 1-21. [CrossRef] [PubMed] 
208. Hartmann, K.; Sepulveda-Falla, D.; Rose, I.V.L.; Madore, C.; Muth, C.; Matschke, J.; Butovsky, O.; Liddelow, S.; Glatzel, M.; Krasemann, S. Complement 3+-astrocytes are highly abundant in prion diseases, but their abolishment led to an accelerated disease course and early dysregulation of microglia. Acta Neuropathol. Commun. 2019, 7, 83. [CrossRef]

209. Yun, S.P.; Kam, T.I.; Panicker, N.; Kim, S.; Oh, Y.; Park, J.S.; Kwon, S.H.; Park, Y.J.; Karuppagounder, S.S.; Park, H.; et al. Block of A1 astrocyte conversion by microglia is neuroprotective in models of Parkinson's disease. Nat. Med. 2018, 24, 931-938. [CrossRef]

210. Johnson, E.C.B.; Dammer, E.B.; Duong, D.M.; Ping, L.; Zhou, M.; Yin, L.; Higginbotham, L.A.; Guajardo, A.; White, B.; Troncoso, J.C.; et al. Large-scale proteomic analysis of Alzheimer's disease brain and cerebrospinal fluid reveals early changes in energy metabolism associated with microglia and astrocyte activation. Nat. Med. 2020, 26. [CrossRef]

211. Bai, B.; Wang, X.; Li, Y.; Chen, P.C.; Yu, K.; Dey, K.K.; Yarbro, J.M.; Han, X.; Lutz, B.M.; Rao, S.; et al. Deep Multilayer Brain Proteomics Identifies Molecular Networks in Alzheimer's Disease Progression. Neuron 2020, 105, 975-991.e7. [CrossRef]

212. Böttcher, C.; Schlickeiser, S.; Sneeboer, M.A.M.; Kunkel, D.; Knop, A.; Paza, E.; Fidzinski, P.; Kraus, L.; Snijders, G.J.L.; Kahn, R.S.; et al. Human microglia regional heterogeneity and phenotypes determined by multiplexed single-cell mass cytometry. Nat. Neurosci. 2019, 22, 78-90. [CrossRef]

213. Neff, E.P. Animal models of Alzheimer's disease embrace diversity. Lab. Anim. 2019, 48, 255-259. [CrossRef]

214. Vandamme, T. Use of rodents as models of human diseases. J. Pharm. Bioallied Sci. 2014, 6, 2-9. [CrossRef]

215. Mariani, J.N.; Zou, L.; Goldman, S.A. Human Glial Chimeric Mice to Define the Role of Glial Pathology in Human Disease. Methods Mol. Biol. 2019, 1936, 311-331. [CrossRef] [PubMed]

216. Benraiss, A.; Wang, S.; Herrlinger, S.; Li, X.; Chandler-Militello, D.; Mauceri, J.; Burm, H.B.; Toner, M.; Osipovitch, M.; Jim Xu, Q.; et al. Human glia can both induce and rescue aspects of disease phenotype in Huntington disease. Nat. Commun. 2016, 7. [CrossRef]

217. Windrem, M.S.; Osipovitch, M.; Liu, Z.; Bates, J.; Chandler-Militello, D.; Zou, L.; Munir, J.; Schanz, S.; McCoy, K.; Miller, R.H.; et al. Human iPSC Glial Mouse Chimeras Reveal Glial Contributions to Schizophrenia. Cell Stem Cell 2017, 21, 195-208. [CrossRef]

218. Han, X.; Chen, M.; Wang, F.; Windrem, M.; Wang, S.; Shanz, S.; Xu, Q.; Oberheim, N.A.; Bekar, L.; Betstadt, S.; et al. Forebrain engraftment by human glial progenitor cells enhances synaptic plasticity and learning in adult mice. Cell Stem Cell 2013, 12, 342-353. [CrossRef]

219. Engel, M.; Do-Ha, D.; Muñoz, S.S.; Ooi, L. Common pitfalls of stem cell differentiation: A guide to improving protocols for neurodegenerative disease models and research. Cell. Mol. Life Sci. 2016, 73, 3693-3709. [CrossRef] [PubMed]

220. Atkinson-Del, R.; Mohamet, L. Induced Pluripotent Stem Cell-Derived Astroglia: A New Tool for Research Towards the Treatment of Alzheimer's Disease; Verkhratsky, A., Ho, M.S., Zorec, R., Parpura, V., Eds.; Springer: Singapore, 2019; Volume 1175.

221. Essayan-Perez, S.; Zhou, B.; Nabet, A.M.; Wernig, M.; Huang, Y.W.A. Modeling Alzheimer's disease with human iPS cells: Advancements, lessons, and applications. Neurobiol. Dis. 2019, 130, 104503. [CrossRef]

Publisher's Note: MDPI stays neutral with regard to jurisdictional claims in published maps and institutional affiliations.

(C) 2020 by the authors. Licensee MDPI, Basel, Switzerland. This article is an open access article distributed under the terms and conditions of the Creative Commons Attribution (CC BY) license (http://creativecommons.org/licenses/by/4.0/). 